\title{
Films based on chitosan polyelectrolyte complexes for skin drug delivery: Development and characterization
}

\author{
Cláudia L. Silva ${ }^{\mathrm{a}, *}$, Jorge C. Pereira ${ }^{\mathrm{b}}$, Amílcar Ramalho ${ }^{\mathrm{c}}$, Alberto A.C.C. Pais ${ }^{\mathrm{b}}$, João J.S. Sousa ${ }^{\mathrm{a}}$ \\ a Faculty of Pharmacy, University of Coimbra, Coimbra, Portugal \\ ${ }^{\mathrm{b}}$ Department of Chemistry, University of Coimbra, Coimbra, Portugal \\ c CEMUC, Department of Mechanical Engineering, University of Coimbra, Coimbra, Portugal
}

\section{A R T I C L E I N F O}

\section{Article history:}

Received 22 December 2007

Received in revised form 31 March 2008

Accepted 4 April 2008

Available online 12 April 2008

\section{Keywords:}

Chitosan

PAA

Polyelectrolyte complexes

Glycerol

Skin drug delivery

\begin{abstract}
A B S T R A C T
Novel chitosan based polyelectrolyte complexes (PEC) were developed and optimized in order to obtain films possessing the optimal functional properties (flexibility, resistance, water vapour transmission rate and bioadhesion) to be applied on skin. The development was based on the combination of chitosan and two polyacrylic acid (PAA) polymers with different crosslinkers and crosslinking densities. The interaction between the polymers was maximized controlling the $\mathrm{pH}$, and by forming the films at a $\mathrm{pH}$ value close to the $\mathrm{p} K_{\mathrm{a}}$ of the respective components as identified by potentiometric and turbidimetric titrations. The action of glycerol, PEG200, Hydrovance and trehalose upon the functional properties of the films was also evaluated. Glycerol was found to improve the film properties in terms of flexibility, resistance and water vapour transmission rate (WVTR) with a maximum effect at $30 \%$. The application of a pressure sensitive adhesive (PSA) significantly improved bioadhesion with a negligible influence in the resistance and flexibility of the films.

The optimized film, including adhesive, has shown very good properties for application in the skin and represents a very promising formulation for further incorporation of drugs for topical and transdermal administration.
\end{abstract}

(C) 2008 Elsevier B.V. All rights reserved.

\section{Introduction}

The systemic drug administration through the skin holds several advantages such as the maintenance of constant drug levels in the blood, decrease of side effects, improvement of bioavailability by circumvention of hepatic first pass metabolism and increased patient compliance [1].

Hydrogels are usually macromolecular three dimensional networks of linear hydrophilic polymers capable of absorbing large amounts of water while remaining insoluble due to the presence of chemical or physical crosslinks [2-4]. Their relatively high water content is important in skin moisturization and elasticity providing a better feel when applied to the skin, making them a good alternative to more conventional dosage forms such as creams, ointments and patches.

The PEC are also, in most cases, preferable to covalently-linked hydrogels because no catalysts or initiators are necessary. Chemical crosslinking agents can induce toxicity and other undesirable effects that require a purification step during manufacturing which

\footnotetext{
* Corresponding author. Tel.: +351 239855085; fax: +351 239855099.

E-mail address: csilva@qui.uc.pt (C.L. Silva).
}

can affect the integrity of the substances to be entrapped [5]. The reaction occurs in aqueous solution and mild conditions [3]. Avoiding the potential toxicity of free unreacted crosslinkers and purification of the hydrogel before administration, favors biocompatibility and enables the direct incorporation of the drug in the formulation during the preparation of the PEC.

The PEC are established by ionic interactions between two oppositely charged polyelectrolytes $[3,4]$. These electrostatic interactions are strong enough to prevent dissolution in water and PEC films are capable of maintaining their mechanical strength $[3,4]$.

Chitosan is a cationic natural biopolymer, non-toxic, biocompatible and non-antigenic [3,6]. It is very abundant [7], ecologically interesting and is a promising carrier for sustained drug release [8]. All these important properties make chitosan a very interesting component of hydrogels in the medical and pharmaceutical fields. In the present work, and since this formulation is intended to be applied to the skin, chitosan was selected as a starting material because of its good film-forming properties, wound-healing benefits, bacteriostatic effects and bioadhesive properties [6,8-12].

Hydrogels composed of chitosan alone are limited by their poor tensile strength (TS), poor elasticity due to its intrinsic chain rigidity and lack of an efficient control of drug delivery $[3,4,13]$. The addition of other polymers is necessary to achieve PEC films with 
improved mechanical strength and elasticity while maintaining all chitosan properties after PEC formation. These systems are biocompatible, well tolerated, suitable as drug delivery systems, for wound management and tissue reconstruction [3]. In this work, PEC are based on chitosan and crosslinked poly(acrylic acid) (PAA) polymers. Hydrogels prepared with a wide range of ratios between chitosan and crosslinked PAA have been successfully prepared for different applications such as the amoxicillin site-specific delivery in stomach $[9,14]$ or the buccal delivery of acyclovir [8] and provided a suitable drug controlled release profile. Crosslinked PAA polymers are water insoluble, have the ability to swell in water and its low glass transition temperature reflects a non-rigid structure [15]. Chitosan, in combination with other polymers and molecules, has been used in several studies of PEC for the controlled delivery of drugs through different routes of administration, e.g., oral [9,16], buccal [8], subcutaneous [17], colonic [18,19], transmucosal [20] and ophthalmic [21].

PEC properties are strongly influenced by two features: the global charge densities of the polymers involved and their relative proportion in the film that is directly related to the degree of interaction between the polymers. The suitability of a hydrogel to work as a drug delivery system and its performance also largely depends on its bulk structure. The main disadvantage of physically crosslinked hydrogels over chemically crosslinked is the lower mechanical stability and the risk of dissolution due to highly $\mathrm{pH}$-sensitive swelling. In the present work, the interaction between the oppositely charged polymers was optimized in order to circumvent this issue. In a first step, the degree of ionization of chitosan and the polyanions was determined as well as the stoichiometry of the polycation/polyanion interactions sites according to the $\mathrm{pH}$ by potentiometric and turbidimetric titrations. The $\mathrm{pH}$ and the amount of each polymer was chosen so as to obtain a ratio of one between the positively charged groups of chitosan and the negatively charged groups of the PAA and thus maximize the number of potential sites for electrostatic interaction. This $\mathrm{pH}$ value was used to prepare all PEC films, based on the assumption that hydrogels with a maximum number of electrostatic interactions would give a tighter structure, improving the stability of the network which would be reflected in a decreased swelling and drug release [9]. Increased crosslinking density and lower degree of swelling also tend to decrease the degree of burst release, minimizing the risk of dose dumping that can be potentially harmful to patients $[22,23]$. In a previous study it was shown that PEC, composed by chitosan and a crosslinked PAA, with the high ionic interactions density showed less $\mathrm{pH}$-dependent swelling-eroding behaviour and exhibited a suitable controlled drug release profile when compared with PEC with low ionic interactions density [24].

The selection of polymers is a very important step in PEC design, since as referred earlier PEC performance will depend on its bulk structure. In this work, two different PAA polymers that have been crosslinked to different extents with allyl pentaerythritol (Carbopol $71 \mathrm{G} \mathrm{NF}^{\circledR}$ ) and divinylglycol (Noveon AA-1 ${ }^{\circledR}$ ) were selected to investigate the influence of the crosslinker in the PEC formation and functional properties. Further, two well known plasticizers, namely, glycerol, and PEG200, a moisturizing agent (Hydrovance ${ }^{\circledR}$ ) and the additive trehalose were added to the PEC at a fixed concentration in order to study their effect on the film properties. Glycerol and PEG200 have demonstrated in earlier studies the ability to increase the flexibility of chitosan films $[25,26]$, while Hydrovance was chosen due to the higher water sorption capacity when compared with glycerol as claimed by the manufacturer. These additives are used in a wide variety of pharmaceutical formulations and have a broad compatibility with other raw materials $[27,28]$.

After selecting the plasticizer with the best performance, its concentration was changed in order to determine the ideal content.
In order to fulfill the therapeutic goals, films designed for skin drug delivery must assure a controlled delivery of the drug. For this purpose the delivery system is required to be bioadhesive [29,30]. This would allow an intimate and prolonged contact with the skin in the application site so as to provide a continuous drug supply as well as flexibility and elasticity sufficient to follow the movements of the skin and provide a good feel. At the same time, it must have enough strength to resist abrasion. In the absence of all or some of these physical and mechanical properties it is difficult to assure a controlled drug release to the skin. Several key properties for the films daily use on the skin and therapeutic efficacy were evaluated: water vapour transmission rate (WVTR), tensile strength, elongation to break(EB), thickness, water sorption and in vivo bioadhesion. Thus, the aim of this study is the development and characterization of PEC films based on chitosan and PAA with good functional properties and cosmetic attractiveness for a potential application as a universal skin drug delivery system.

Due to the small bioadhesive properties of the formulations, an additional layer of a hydrophilic PSA composed of long chain PVP and PEG400 was applied to the film with the best functional performance and the properties of the resulting formulation were equally evaluated. This PVP-PEG400 PSA has been designed for enhanced transdermal delivery of drugs, is compatible with drugs of different physicochemical properties, does not act as a barrier to drug diffusion and is non-toxic [31-33]. We have decided to apply a hydrophilic PSA in order to keep the hydrophilic nature of the skin delivery system and because this type of adhesives offers several advantages over the hydrophobic ones: improved skin adhesion, compatibility with a higher variety of drugs and excipients, and expanded capability to control/manipulate adhesion-cohesive properties [34]. This PSA exhibits all the ideal properties for the development of a universal matrix for the skin delivery of drugs.

The interaction between chitosan and PAA was investigated by differential scanning calorimetry (DSC) and Fourier Transform Infrared-Attenuated Total Reflectance (FTIR-ATR).

\section{Materials and methods}

\subsection{Materials}

Low molecular weight chitosan was purchased from Sigma-Aldrich Corp., St. Louis, Missouri, USA. Noveon AA-1 ${ }^{\circledR}$ and Carbopol 71G $\mathrm{NF}^{\circledR}$ were a gift from Lubrizol Advance Materials Inc. (Cleveland, Ohio, USA) and Hydrovance ${ }^{\circledR}$ was kindly provided by National Starch \& Chemical Company (Bridgewater, New Jersey, USA). Propylene glycol, trehalose, PEG200 and polyvinylpyrrolidone K90 (PVP K90) were obtained from Fluka Chemie GmbH (Buchs, Switzerland). All other chemical reagents were of pharmaceutical grade.

\subsection{Potentiometric titration}

Solutions with a concentration of $0.1 \%(\mathrm{w} / \mathrm{v})$ of Noveon and Carbopol and a solution of $0.1 \%(\mathrm{w} / \mathrm{v})$ of chitosan in $2 \%$ lactic acid $(\mathrm{w} / \mathrm{v}$ ) were acidified by adding $2 \mathrm{~mL}$ of $1 \mathrm{M} \mathrm{HCl}$. The solutions were titrated with standardized $0.5 \mathrm{M} \mathrm{NaOH}$ in a Metrohm AG (Herisau, Switzerland) water-jacketed titration vessel, thermostated at 25.0 $( \pm 0.1){ }^{\circ} \mathrm{C}$ with a microburette in the presence of an inert atmosphere $\left(\mathrm{N}_{2}\right)$. Potentiometric titrations were conducted with a 665 DOSIMATE (Metrohm AG, Herisau, Switzerland) microburette with minimal volume increments of $0.001 \mathrm{~mL}$, recorded with a pHM 95 potentiometer $( \pm 0.1 \mathrm{mV})$ (Radiometer Analytical SAS, Lyon, France). Potentiometric titration end point was estimated by the inflection point of the titration curve [35]. Overall ioniza- 
tion constant was estimated using the highest buffering capacity

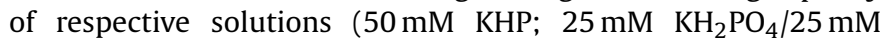
$\mathrm{Na}_{2} \mathrm{HPO}_{4} ; 25 \mathrm{mM} \mathrm{NaHCO} / 25 \mathrm{mM} \mathrm{Na}_{2} \mathrm{CO}_{3}$ ), i.e. equimolar acid and base forms [36]. $\mathrm{pH}$ values were obtained via a three standard buffers calibration ( $\mathrm{pH} 4.00,6.86$ and 10.0) under similar experimental conditions.

\subsection{Turbidimetric titration}

Turbidimetric measurements were carried out with a UV spectrophotometer (Shimadzu UV visible 1603, Shimadzu Scientific Instruments, Kyoto, Japan) at the wavelength $\lambda=420 \mathrm{~nm}[8,16,37]$. Solutions of $0.05 \%(\mathrm{w} / \mathrm{v})$ of Carbopol and Noveon in distilled water and $0.1 \%$ of chitosan $(\mathrm{w} / \mathrm{v})$ in $0.1 \%$ lactic acid solution $(\mathrm{w} / \mathrm{v})$ were prepared. The titrant $(\mathrm{HCl} 1 \mathrm{M}$ and $\mathrm{NaOH} 1 \mathrm{M}$, respectively) was delivered with a microsyringe into the solution with gentle magnetic stirring at ambient temperature, until a stable reading was obtained. The $\mathrm{pH}$ was monitored with a digital $\mathrm{pH}$ meter and changes in turbidity are reported in arbitrary units as $100-\% T$, linearly proportional to the true turbidity for $T>0.9$ [16]. Turbidity values are given as a function of the $\mathrm{pH}$ of the solutions.

\subsection{Preparation of the chitosan-polyacrylic acid polyelectrolyte complexes (PEC) films}

Chitosan solutions $(1 \%, \mathrm{w} / \mathrm{v})$ were prepared by dispersing chitosan in $0.5 \%(\mathrm{w} / \mathrm{v})$ aqueous lactic acid solution $[38,39]$ and stirring overnight. Lactic acid was used to solubilize chitosan because it has been proven to be non-irritating relative to other alternatives, such as acetic acid, on rabbit skin and has the ability to improve the flexibility of the film due to a plasticizing action [38,39]. Low molecular weight chitosan was chosen because it has been suggested to react more completely with polyanions compared with chitosan of higher MW and originates films with smoother surfaces [40]. PAA polymers were dissolved in ultrapure water (Durapore $(0.22 \mu \mathrm{m})$, Millipore, Bedford, MA) and the $\mathrm{pH}$ of the solutions was adjusted by addition of $1 \mathrm{M} \mathrm{HCl}$ until the degree of ionization was less than $0.1 \%$ in order to avoid precipitation when mixing the solutions of the polymers, and obtain a homogeneous mixture [3]. The chitosan solution is dropwise added to the PAA suspensions and mixed with a mechanical stirrer. The relative amount of both polymers was determined by the potentiometric titrations in order to obtain charge neutralization between the positively charged and negatively charged polymers at the $\mathrm{pH}$ where the ratio between the positive charges and negative charges is approximately one.

The concentration of each additive incorporated is given in percentage (\%) and is related to the total dry weight of the polymers.
After addition of the plasticizers, the suspension was neutralized with $\mathrm{NaOH} 1 \mathrm{M}$ to reach a $\mathrm{pH}$ of 6.1.

Film forming solutions were magnetically stirred for $3 \mathrm{~h}$, cast on Petri-dishes and dried at $35^{\circ} \mathrm{C}$ for about $48 \mathrm{~h}$. Dried films were conditioned in a desiccator containing a saturated solution of $\mathrm{NaCl}$ at $25^{\circ} \mathrm{C}(75 \% \mathrm{RH})$ [41].

An adhesive solution composed of 67 wt\% PVP K90 and 33 wt\% PEG400 in ethanol was applied to the PEC film with the best functional performance (see below) by solvent casting technique. PVP and PEG400 are miscible in a very wide composition range but only display adequate PSA properties between 30 and $40 \mathrm{wt} \%$ PEG400 [42]. PVP-PEG400 blends with 36\% PEG400 showed in earlier studies the best adhesion performance $[34,42]$ but in pre-formulation studies in our lab for this particular type of film, the best adhesion/cohesive properties were obtained for $33 \mathrm{wt} \%$ PEG400.

Table 1 summarizes the PEC compositions, and the coding used in what follows.

\subsection{Scanning electron microscopy (SEM)}

The films were mounted on an aluminium sample support by means of a conductive and double-sided adhesive tape after which they were freeze-dried (Freeze-Drier Labconco FreeZone 4.5, Labconco, Kansas City, MO, USA). The morphologies of the film surfaces and cross-sections were analyzed using a Philips XL30 TMP Scanning Electron Microscope (Philips, Amsterdam, Netherlands) with a Secondary Electron (SE) detector at an acceleration voltage of ca. $800 \mathrm{eV}$. The images were taken without the use of a metal coating.

\subsection{Mechanical properties}

Tensile strength and elongation to break (\%) were measured on test strips after their equilibration for at least $72 \mathrm{~h}$ in a desiccator containing a saturated solution of $\mathrm{NaCl}$ at $25^{\circ} \mathrm{C}(75 \% \mathrm{RH})$ [41] using a TA.XTPlus Texture analyzer (Stable Micro Systems, Surrey, UK) equipped with a tension grip system. All samples were cut with scissors into bars of $15 \mathrm{~mm} \times 50 \mathrm{~mm}$ before equilibration. In this experiment, at least four determinations were performed for each film type.

The TS is calculated by dividing the maximum breaking force $(\mathrm{N})$ by the cross-sectional area $\left(\mathrm{mm}^{2}\right)$ of each film. EB (\%) is the ratio between the extension of the film at the point of rupture and the initial length of the sample and is expressed in percentage.

Film thickness was measured with a hand-held micrometer and six replicates were taken on each specimen in different places. Mean values and mean standard deviations were calculated for the film TS and EB\%.

\section{Table 1}

Composition (\%,w/w) and coding for each PEC film prepared in this work

\begin{tabular}{|c|c|c|c|c|c|c|c|c|}
\hline & Chitosan & Carbopol & Noveon & Glycerol & PEG200 & Hydrovance & Trehalose & PSA \\
\hline$F_{C}$ & 67.6 & 32.4 & & & & & & \\
\hline$F_{C G}$ & 67.6 & 32.4 & & 20 & & & & \\
\hline $\mathrm{F}_{\mathrm{CP}}$ & 67.6 & 32.4 & & & 20 & & & \\
\hline $\mathrm{F}_{\mathrm{CH}}$ & 67.6 & 32.4 & & & & 20 & & \\
\hline $\mathrm{F}_{\mathrm{CT}}$ & 67.6 & 32.4 & & & & & 20 & \\
\hline $\mathrm{F}_{\mathrm{N}}$ & 65.4 & & 34.6 & & & & & \\
\hline $\mathrm{F}_{\mathrm{NG}}$ & 65.4 & & 34.6 & 20 & & & & \\
\hline $\mathrm{F}_{\mathrm{NP}}$ & 65.4 & & 34.6 & & 20 & & & \\
\hline $\mathrm{F}_{\mathrm{NH}}$ & 65.4 & & 34.6 & & & 20 & & \\
\hline $\mathrm{F}_{\mathrm{NT}}$ & 65.4 & & 34.6 & & & & 20 & \\
\hline $\mathrm{F}_{\mathrm{N} 30 \mathrm{G}}$ & 65.4 & & 34.6 & 30 & & & & \\
\hline $\mathrm{F}_{\mathrm{N} 40 \mathrm{G}}$ & 65.4 & & 34.6 & 40 & & & & \\
\hline $\mathrm{F}_{\mathrm{Na}}$ & 65.4 & & 34.6 & 30 & & & & 1 layer \\
\hline
\end{tabular}

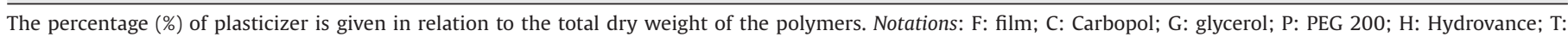
Trehalose; N: Noveon; 30G: 30\% glycerol; 40G: 40\% glycerol; a: PSA. 


\subsection{Water sorption (\%)}

Water sorption was assessed gravimetrically. The films were freeze-dried (Freeze-Drier Labconco FreeZone 4.5, Labconco, Kansas City, MO, USA) and after drying the weight of each film was measured. The films were successively transferred to vacuum desiccators over saturated salt solutions of $\mathrm{LiCl}(11 \% \mathrm{RH}), \mathrm{NaBr}(60 \%$ $\mathrm{RH}), \mathrm{NaCl}(75 \% \mathrm{RH})$ and ultrapure water $(100 \% \mathrm{RH})$ at $25^{\circ} \mathrm{C}$ [41]. All the salts were of reagent grade.

The samples were left to equilibrate for a minimum of 3 days before new weight measurement with an analytical balance and three replicates were tested for each type of film.

Water sorption of the film is given in what follows as the increase in weight, expressed as a percentage.

\subsection{Water vapour transmission rate}

The water vapour transmission rate $\left(\mathrm{g} \mathrm{m}^{-2} \mathrm{~h}^{-1}\right)$ was measured using a Vapometer (Delfin Technologies Ltd., Kuopio, Finland). Briefly, films specimens were mounted and sealed in the top of open specially designed cups filled with distilled water up to $1.1 \mathrm{~cm}$ from the film underside and left to equilibrate for $1 \mathrm{~h}$ at room temperature $\left(22-23^{\circ} \mathrm{C}, 42-46 \% \mathrm{RH}\right)$. The Vapometer has a closed measuring chamber not sensitive to external airflows with a humidity sensor that enable measurements in normal room conditions [43]. Three film samples were tested for each type of film.

\subsection{In vivo bioadhesive properties}

The in vivo evaluation of the bioadhesive properties of the films, including peak adhesion force (PAF) and work of adhesion (WA), was performed using a TA.XTPlus Texture analyzer (Stable Micro Systems, Surrey, UK). The film was fixed by means of a doublesided adhesive tape on the movable carriage of the apparatus. The carriage is moved until contact between the skin of the subject forearm and the movable carriage is established. A preload of $3 \mathrm{~N}$ was applied and the contact time of the holder and the skin was $60 \mathrm{~s}$. After that time, the movable carriage is moved forward at a constant speed test of $10 \mathrm{~mm} / \mathrm{s}$ until complete separation of the two surfaces. The curves of displacement $(\mathrm{mm})$ versus adhesive force $(\mathrm{mN})$ are recorded simultaneously. The WA is given by the integral on the range of positive force.

The force required to detach the attached film from the human forearm skin was used to represent the magnitude of bioadhesive force of the tested film specimen.

\subsection{Differential scanning calorimetry analysis}

The DSC analysis was used to characterize the thermal behaviour of the polymer powders and the interactions between the polymers in the films. DSC thermograms were obtained using a Shimadzu DSC-50 System (Shimadzu, Kyoto, Japan) with nitrogen at a rate of $20 \mathrm{~mL} / \mathrm{min}$ as purge gas. Approximately $2-5 \mathrm{mg}$ of each freeze-dried sample was accurately weighted into aluminium pans and hermetically sealed. The DSC runs were conducted from room temperature to $400^{\circ} \mathrm{C}$ at a heating rate of $10^{\circ} \mathrm{C} / \mathrm{min}$. Each sample was run in triplicate.

\subsection{Fourier Transform Infrared-Attenuated Total Reflectance analysis}

The FTIR-ATR spectra of the dried pure polymers and the films were recorded with a Magna-IR ${ }^{\mathrm{TM}}$ spectrophotometer 750 (Thermo Nicolet, Madison, Wisconsin, USA) using the ATR sampling technique on a ZnSe crystal. Samples were scanned 64 times over the wavenumber range of $400-4000 \mathrm{~cm}^{-1}$ with a resolution of $4 \mathrm{~cm}^{-1}$.

\subsection{Statistical analysis}

Results are expressed as mean \pm standard error (S.E.). The significance of the differences between values was assessed using a two sample $t$-test with a statistical significance level set at $P<0.05$.

\section{Results and discussion}

\subsection{Potentiometric and turbidimetric titrations}

Potentiometric titrations were performed in order to evaluate the pH-dependent ionization degree of chitosan, Noveon and Carbopol, the stoichiometry of the polycation/polyanion interactions and the chitosan degree of deacetylation $[35,44]$.

The $\mathrm{p} K_{\mathrm{a}}$ values obtained from the potentiometric titration curves were 6.22, 6.11 and 6.09 for chitosan, Carbopol and Noveon, respectively and the number of miliequivalents acids per gram of polymer (meq. $\mathrm{g}^{-1}$ ) are $5.45,12.86$ and 11.48 , respectively. The values determined for Carbopol and Noveon differ by only ca. $11 \%$, as could be expected since they only differ in the type of crosslinker and crosslinking extent. The degree of ionization of each polymer was calculated in order to determine the stoichiometry of the chitosan/Carbopol and chitosan/Noveon interactions according to the pH and is depicted in Fig. 1.

It is well known that the charge densities of the polycation (chitosan) and the polyanions (Carbopol and Noveon) are mainly controlled by the $\mathrm{pH}$. The $\mathrm{pH}$ value at which the ionization curve (Fig. 1) of the polycation intercepts the ionization curves of the polyanions was considered the ideal $\mathrm{pH}$ for the preparation of the polyelectrolyte complexes due to the maximization of the number of potential electrostatic interaction sites. In both Carbopol and Noveon the ideal $\mathrm{pH}$ found for the interaction with chitosan was 6.1. With this value it is possible to calculate the amount of the polycation and polyanion that should be mixed in order to impose a charge ratio of one (see Table 1 ).

The potentiometric titration also enabled the calculation of the degree of deacetylation of chitosan. It corresponds to $88 \%$ in the polymer used in the present work.

The maximum degree of swelling in each PEC is determined by the balance between repulsion and contractile forces within the network. If there is a high degree of swelling, the complex can be dissolved. If we are maximizing the grade of network complexation through the maximization of the number of the electrostatic interactions between the two oppositely charged polymers, we are

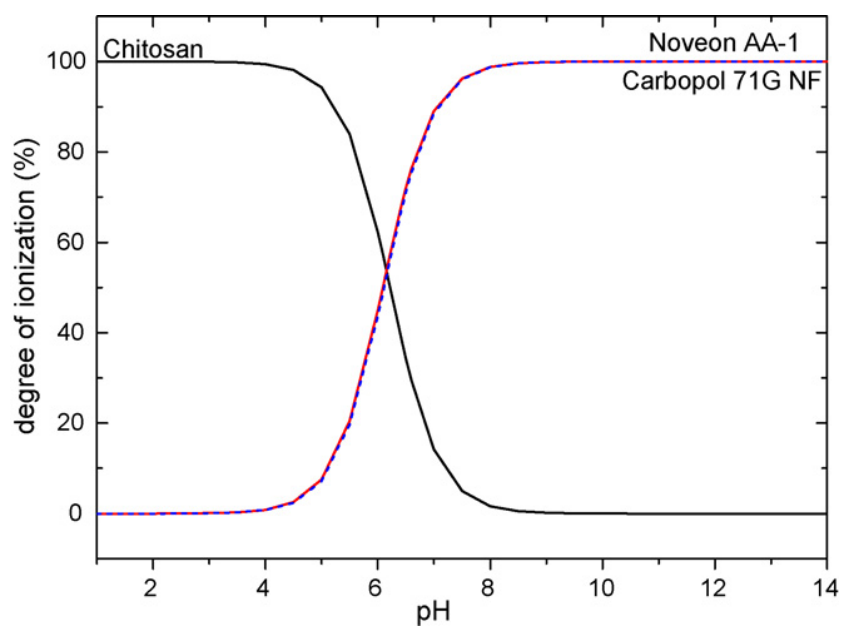

Fig. 1. Degree of ionization of chitosan, Carbopol and Noveon according to pH. The ionization curves of Carbopol and Noveon are superimposed. 


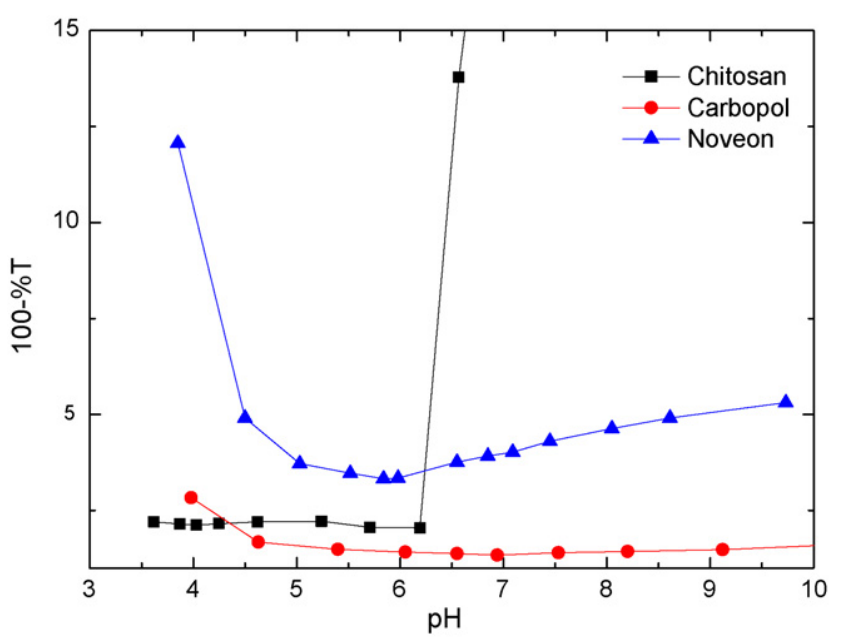

Fig. 2. Turbidity of chitosan, Carbopol and Noveon as a function of pH. Values are reported in arbitrary units as $100-\% T$.

increasing the stability of the network, that will lead to a reduction of the swelling/eroding behaviour of the PEC and, as a consequence, the tighter network will exhibit properties that allow the controlled release of drugs without the need of crosslinkers [9,24].

Turbidimetric titrations consist in the measurement of the decrease in the intensity of a light flow passing through a solution with particles in suspension and is proportional to both molecular weight and the concentration of the particles in the solution [45]. High turbidity indicates a high precipitation of the particles that occurs when the polymers are neutralized. In Fig. 2 we can see the results of the turbidimetric measurements for the three polymers.
These results are in very good agreement with the degree of ionization calculated from the results of the potentiometric titrations. Turbidity of Carbopol solutions is less influenced by $\mathrm{pH}$ when compared with the Noveon solution and at $\mathrm{pH} 6.1$ all three polymers exhibit a small turbidity indicating a high degree of ionization.

\subsection{Characterization of films}

The PEC films prepared are thin (see Table 2), transparent and slightly yellow due to the high content of chitosan. Fig. 3 shows the scanning electron micrographs of the different freeze-dried PEC films at the same magnification. The surface morphology of the all films is quite smooth and uniform while the cross-sectional morphology is very dense and uniform. These observations agree with the assumption that hydrogels with a maximum number of electrostatic interactions have a tight structure and improved network stability.

\subsubsection{Mechanical properties}

The TS and the EB\% are important mechanical properties for the characterization of PEC films in terms of their resistance to abrasion and flexibility, respectively. Films intended for skin drug delivery must be flexible enough to follow the movements of the skin and provide a good feel, and at the same time resist the mechanical abrasion caused, for example, by clothes. For simplicity we consider that a film for skin drug delivery should be hard (high TS) and tough (high EB\%) [46].

The TS values of the PEC films with $20 \%$ plasticizer are shown in Fig. 4(a). The values range from 2.7 to $5.8 \mathrm{~N} / \mathrm{mm}^{2}$ and are referred to films $\mathrm{F}_{\mathrm{CH}}$ and $\mathrm{F}_{\mathrm{NG}}$, respectively. Comparison with the values found by other authors is difficult due to the different techniques used to determine TS and lack of standardization.

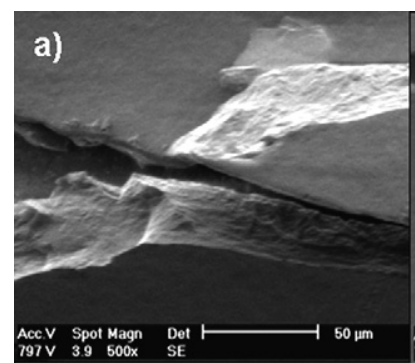

e)
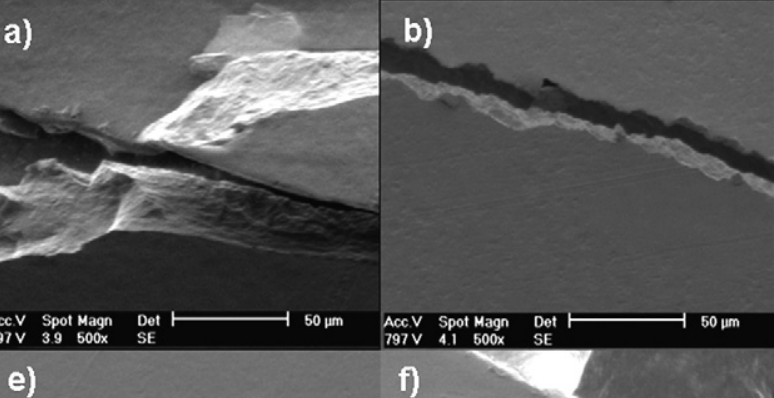

f)
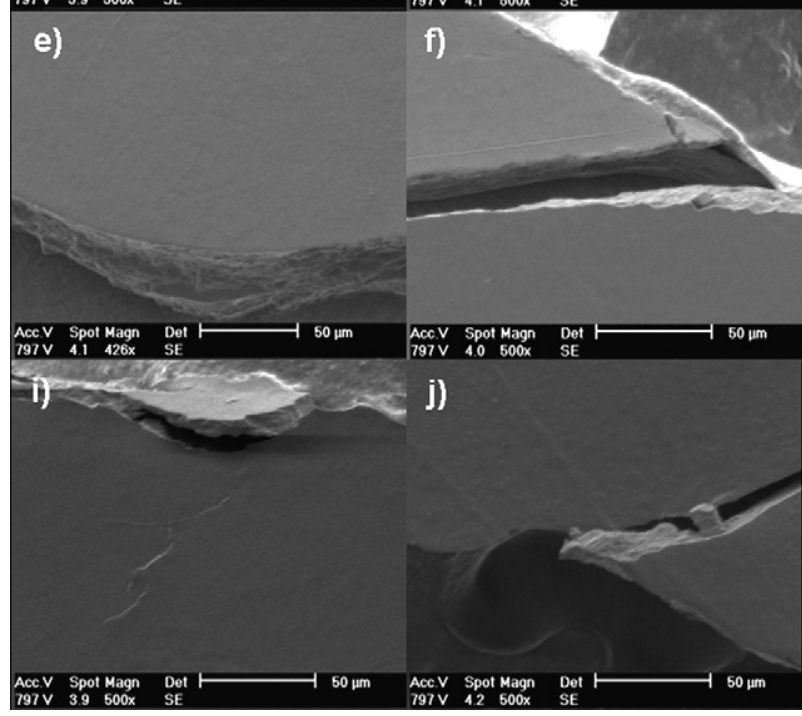

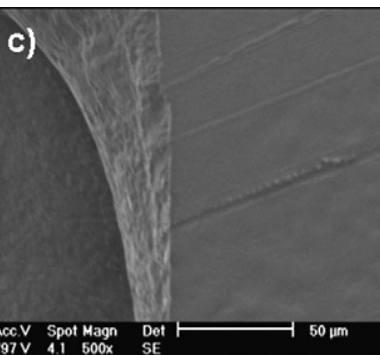

d)
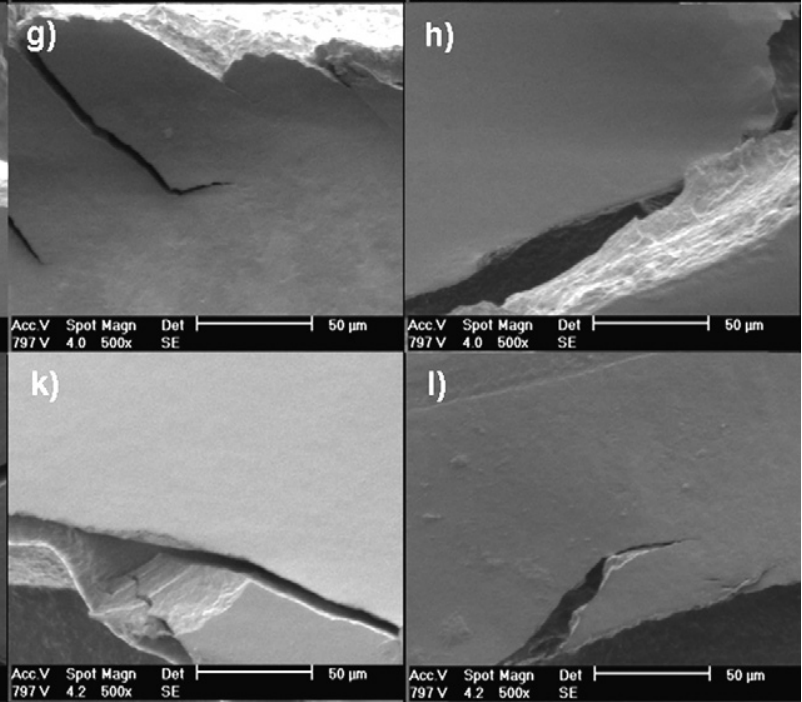

I)

h)

Fig. 3. Scanning electron micrographs of freeze-dried PEC films: (a) $F_{C}$, (b) $F_{C P}$, (c) $F_{C H}$, (d) $F_{C T}$, (e) $F_{C G}$, (f) $F_{N}$, (g) $F_{N P}$, (h) $F_{N H}$, (i) $F_{N T}$, (j) $F_{N G}$, (k) $F_{N 30 G}$ and (l) $F_{N 40 G}$. 
Table 2

Bioadhesion, WVTR and thickness of the different PEC films according to the coding of Table 1 (for clarity values for reference films are presented in bold font)

\begin{tabular}{|c|c|c|c|c|}
\hline & \multicolumn{2}{|c|}{ In vivo bioadhesion } & \multirow[t]{2}{*}{ WVTR $\left(\mathrm{g} \mathrm{m}^{-2} \mathrm{~h}^{-1}\right)$} & \multirow[t]{2}{*}{ Thickness $(\mu \mathrm{m})$} \\
\hline & $\operatorname{PAF}\left(\mathrm{mN} / \mathrm{cm}^{2}\right)$ & $\mathrm{WA}\left(\mathrm{mJ} / \mathrm{cm}^{2}\right)$ & & \\
\hline $\mathrm{F}_{\mathrm{C}}$ & $71.5 \pm 8.2$ & $6.4 \times 10^{-5} \pm 1.4 \times 10^{-5}$ & $14.5 \pm 0.3$ & $95.0 \pm 4.5$ \\
\hline $\mathrm{F}_{\mathrm{CG}}$ & $105.8 \pm 8.3^{*}$ & $13.0 \times 10^{-5} \pm 1.3 \times 10^{-5^{*}}$ & $14.4 \pm 0.2$ & $92.5 \pm 3.1$ \\
\hline $\mathrm{F}_{\mathrm{CP}}$ & $64.1 \pm 4.5$ & $5.2 \times 10^{-5} \pm 4.4 \times 10^{-5}$ & $14.5 \pm 0.4$ & $120.0 \pm 9.7^{*}$ \\
\hline $\mathrm{F}_{\mathrm{CH}}$ & $65.2 \pm 4.9$ & $6.4 \times 10^{-5} \pm 9.0 \times 10^{-6}$ & $13.4 \pm 0.3^{*}$ & $100.0 \pm 5.9$ \\
\hline $\mathrm{F}_{\mathrm{CT}}$ & $105.0 \pm 6.6^{*}$ & $12.1 \times 10^{-5} \pm 3.7 \times 10^{-5}$ & $14.3 \pm 0.1$ & $102.5 \pm 1.1$ \\
\hline $\mathrm{F}_{\mathrm{N}}$ & $68.9 \pm 9.4$ & $5.7 \times 10^{-5} \pm 1.2 \times 10^{-5}$ & $14.2 \pm 0.2$ & $90.8 \pm 2.4$ \\
\hline $\mathrm{F}_{\mathrm{NG}}$ & $127.4 \pm 15.2^{*}$ & $14.3 \times 10^{-5} \pm 1.8 \times 10^{-5^{*}}$ & $18.1 \pm 0.3^{*}$ & $100.8 \pm 2.7^{*}$ \\
\hline $\mathrm{F}_{\mathrm{NP}}$ & $69.1 \pm 2.4$ & $7.8 \times 10^{-5} \pm 9.2 \times 10^{-6}$ & $14.8 \pm 0.2$ & $107.5 \pm 6.7^{*}$ \\
\hline $\mathrm{F}_{\mathrm{NH}}$ & $62.5 \pm 3.4$ & $5.3 \times 10^{-5} \pm 8.5 \times 10^{-6}$ & $15.3 \pm 0.3^{*}$ & $96.7 \pm 2.5$ \\
\hline $\mathrm{F}_{\mathrm{NT}}$ & $57.9 \pm 4.2$ & $4.9 \times 10^{-5} \pm 4.3 \times 10^{-6}$ & $14.2 \pm 0.2$ & $98.3 \pm 3.3$ \\
\hline $\mathrm{F}_{\mathrm{N} 30 \mathrm{G}}$ & $64.0 \pm 2.3$ & $6.2 \times 10^{-5} \pm 8.6 \times 10^{-7}$ & $20.1 \pm 0.2^{*}$ & $105.8 \pm 2.4$ \\
\hline $\mathrm{F}_{\mathrm{N} 40 \mathrm{G}}$ & $117.2 \pm 14.4^{*}$ & $13.6 \times 10^{-5} \pm 1.0 \times 10^{-5^{*}}$ & $19.2 \pm 0.3^{*}$ & $89.3 \pm 1.7$ \\
\hline $\mathrm{F}_{\mathrm{Na}}$ & $885.4 \pm 62.2^{*}$ & $311.2 \times 10^{-5} \pm 1.5 \times 10^{-4^{*}}$ & $14.2 \pm 0.3$ & $102.5 \pm 4.8$ \\
\hline
\end{tabular}

Results are expressed as mean ( \pm S.E.), $n>3$ (bioadhesion), $n=9$ (WVTR), $n=6$ (thickness).

Statistically significant difference in comparison with the film in the absence of the additive $(P<0.05)$.
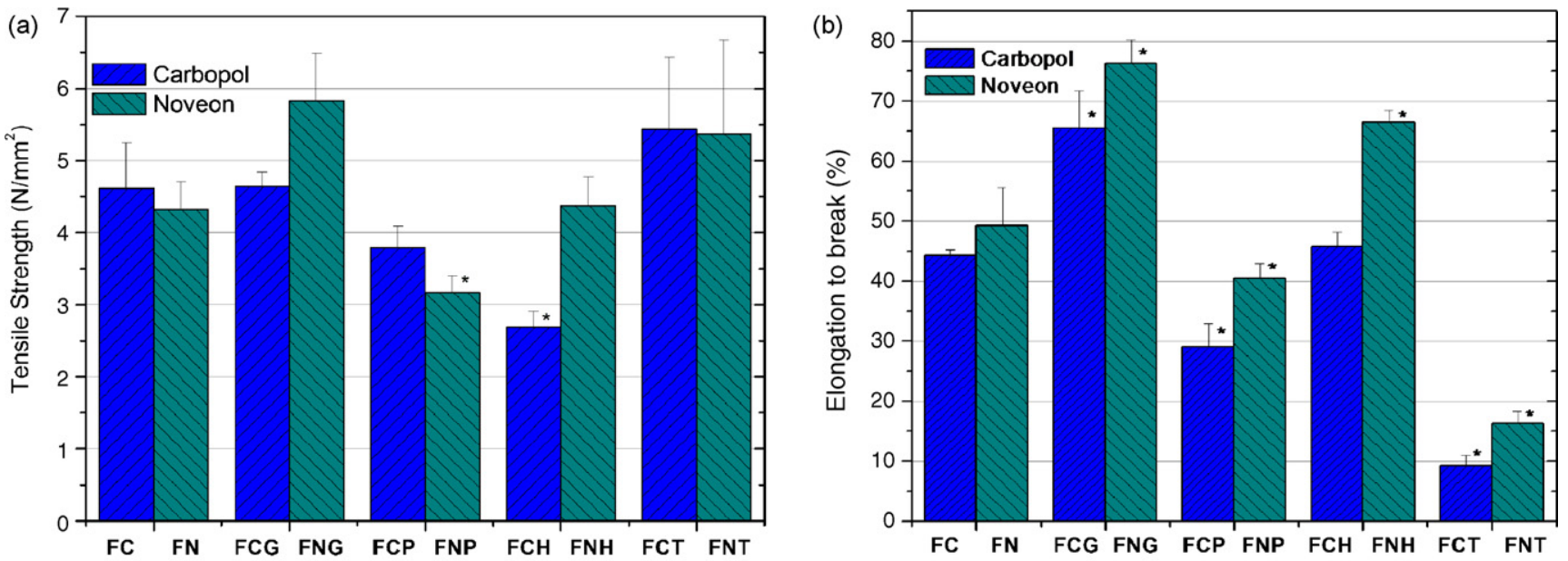

(c)

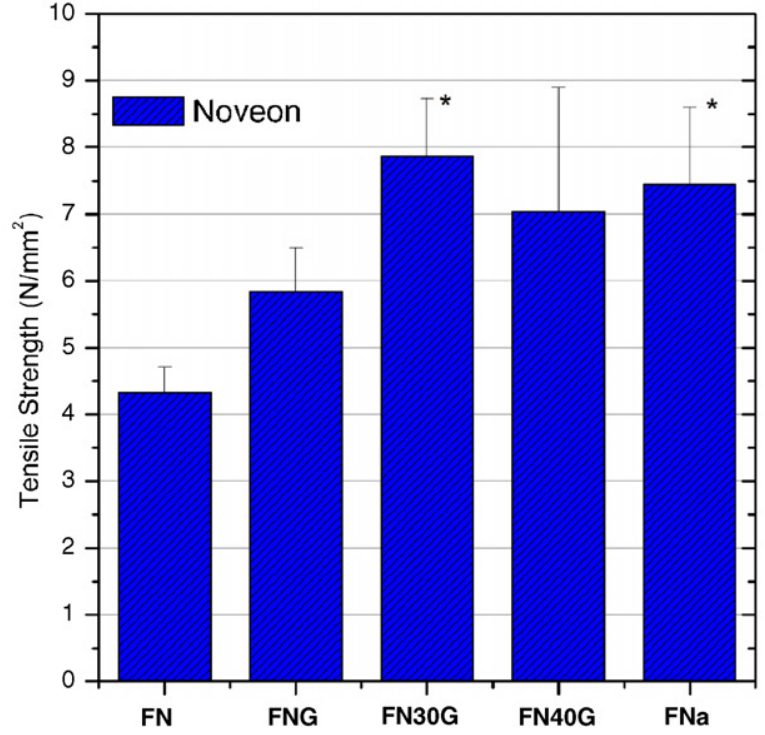

(d)

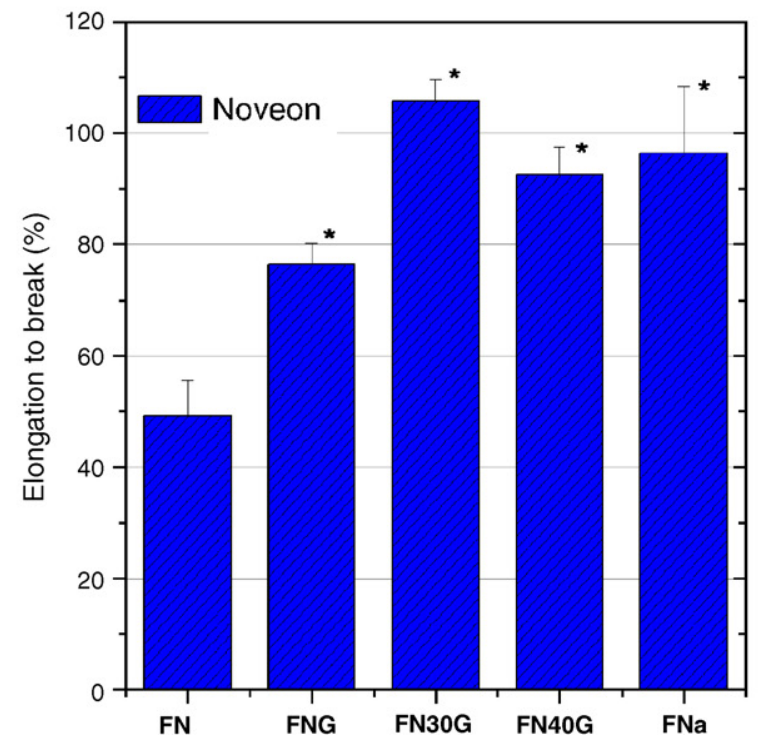

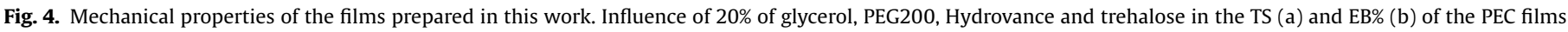

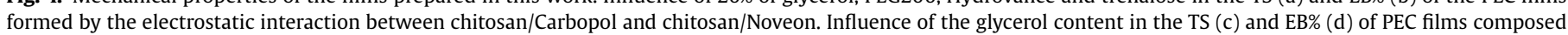

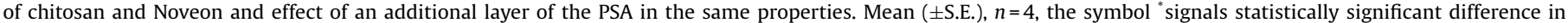
comparison with the film in the absence of the additive $(P<0.05)$. 
It is found that 20\% PEG200 in the case of $\mathrm{F}_{\mathrm{NP}}$ and $20 \%$ Hydrovance in $\mathrm{F}_{\mathrm{CH}}$ films adversely affect the TS with statistical significance $(P<0.05)$ when compared with the films in the absence of plasticizer (Fig. 4(a)).

The EB\% values measured for the films at constant (20\%) plasticizer content are shown in Fig. 4(b) and range from 9.2 to $76.4 \%$, being $\mathrm{F}_{\mathrm{CT}}$ and $\mathrm{F}_{\mathrm{NG}}$ the films with the smallest and the highest $\mathrm{EB} \%$ values. For the case of chitosan/Noveon films the values of EB\% increased in the following order $\mathrm{F}_{\mathrm{NT}}<\mathrm{F}_{\mathrm{N}} P<\mathrm{F}_{\mathrm{N}}<\mathrm{F}_{\mathrm{NH}}<\mathrm{F}_{\mathrm{NG}}$ while for the case of chitosan/Carbopol films the EB\% values increased in the following order $\mathrm{F}_{\mathrm{CT}}<\mathrm{F}_{\mathrm{C}} P<\mathrm{F}_{\mathrm{C}} \sim \mathrm{F}_{\mathrm{CH}}<\mathrm{F}_{\mathrm{CG}}$, see Fig. 4(b). This indicates that trehalose and PEG200 always decrease the flexibility of the films and that glycerol is the plasticizer that produces the highest increase in the $\mathrm{EB} \%$ with statistical significance $(P<0.05)$. In the case of Hydrovance it can be seen that only in the $\mathrm{F}_{\mathrm{NH}}$ film it was able to significantly increase $(P<0.05)$ the EB\%. It should also be noticed that chitosan/Carbopol films exhibit a lower flexibility when compared with chitosan/Noveon films with the same plasticizers. According with the presented results of TS and $\mathrm{EB} \%, \mathrm{~F}_{\mathrm{NG}}$ is the film that presents the best functional properties for the skin drug delivery because it presents the highest values of TS and EB\%. Glycerol was than selected to proceed the study and its concentration was further changed.

Fig. 4(c) and (d) depicts the influence of the glycerol content in the TS and EB\% of the films containing Noveon. It is clear that increasing amounts of glycerol tend to increase the mean values of both TS and EB\% with the maximum effect at 30\% glycerol. In fact $30 \%$ glycerol produced a statistically significant difference $(P<0.05)$ of both TS and EB\% while $40 \%$ glycerol produced only a statistically significant difference $(P<0.05)$ in the EB\%. In other study glycerol also demonstrated the capacity to increase the TS and EB\% of chitosan films [47] but in most of the studies glycerol exhibits the typical plasticizing effect (decreases TS while increases $\mathrm{EB} \%)[25,48,49]$. Glycerol reduces the rigidity of the bulk polymer network, originating films with increased polymer chain movements (increases EB\%) probably due to the higher water content determined in the water sorption measurements (see below) in comparison with the films without glycerol. The increased TS may be explained by a negligible influence in the polymer-polymer interactions and possibly by the interaction with the polymers chains through the formation of hydrogen bonds.

The expected effect of a plasticizer is a decrease in the TS and an increase in the EB\% $[26,46]$. It is shown that trehalose exhibits an "antiplasticization" effect [26] because it increases TS and decreases EB\% and none of the molecules tested acts as a true plasticizer $[26,46]$. A strong interaction between trehalose and the polymers might be occurring, decreasing the molecular mobility of the polymers. Another explanation may be a reduced moisture uptake capacity of the films with trehalose that is observed in the water sorption isotherms (see below), such that we observe a reduced plasticizing effect due to a smaller amount of water present in the films.

$\mathrm{F}_{\mathrm{N} 30 \mathrm{G}}$ was considered the film with the best functional performance and an additional layer of a hydrophilic PSA was applied due to the small bioadhesive properties determined for the PEC films alone (see Section 3.2.4). The influence of this new layer in the TS and EB\% of the formulation was also investigated and can be seen in Fig. 4(c) and (d). It is seen that the adhesive layer induces a minimum decrease of both TS and EB\% when compared with $\mathrm{F}_{\mathrm{N} 30 \mathrm{G}}$ but the values measured in the bilayer film $\left(\mathrm{F}_{\mathrm{Na}}\right)$ still show an improvement of both TS and EB\% with statistical significance $(P<0.05)$, when compared with the film in the absence of any plasticizer $\left(F_{N}\right)$.

In summary, chitosan/Noveon films are shown to be more flexible than the correspondent chitosan/Carbopol films. PEG200 and trehalose decrease the flexibility of the films and glycerol improves both flexibility and resistance, with a maximum effect at $30 \%$. The properties of the optimized film $\left(\mathrm{F}_{\mathrm{Na}}\right)$ are thus extremely adequate for application in the skin, since it exhibits a higher flexibility (high $\mathrm{EB} \%$ ) and higher TS than the control film $\left(\mathrm{F}_{\mathrm{N}}\right)$ that anticipates a higher capacity to follow the movements of the skin while resisting the mechanical abrasion. These properties are very important not only to provide a comfortable wear but also to provide a continuous drug supply to the skin.

\subsubsection{Water sorption (\%)}

Water sorption isotherms are important for providing some understanding in what concerns the interaction mechanism between water and film components and were also determined in order to know the water content of the films used in the tensile experiments. Considering that these films are intended to be applied on the skin for a long time, the water sorption isotherms reflect how the water content of the films changes with the ambient $\mathrm{RH}$, a determinant parameter for the mechanical properties of the films. An ideal patch should keep its mechanical properties over a wide range of $\mathrm{RH}$.

The water sorption in hydrophilic polymers is usually a nonlinear process. Crosslinked PAA and chitosan are hydrophilic polymers that are able to retain a considerable amount of water that depends on the RH. In chitosan we can find at least three main sites for water absorption: hydroxyl groups, the amino group and the polymer chain end (a hydroxyl or an aldehyde group) [50].

The water sorption uptake of all films increases with increasing $\mathrm{RH}$ and is more pronounced at high RH, Fig. 5.

In the case of the films with or without $20 \%$ of additives we can find two types of water sorption curves. Films $\mathrm{F}_{\mathrm{CH}}, \mathrm{F}_{\mathrm{CT}}, \mathrm{F}_{\mathrm{N}}$, $\mathrm{F}_{\mathrm{NH}}$ and $\mathrm{F}_{\mathrm{CT}}$ exhibit a slightly sigmoidal shape typical of polymers and films, including chitosan [49,51,52]. The water sorption curve can be divided in two regimes, at low RH there is a low amount of water absorbed followed by a regime where the amount of water uptake increases exponentially. Films $F_{C}, F_{C G}, F_{C P}, F_{N P}$ and $F_{N G}$ show a different and atypical sorption curve that can be divided in three different regimes: at low $\mathrm{RH}(<40 \% \mathrm{RH})$ there is a small amount of water absorbed, followed by a second regime where there is an exponential increase in the water sorption rate and finally, for $\mathrm{RH}$ higher than $75 \% \mathrm{RH}$ the water sorption rate has a small decrease. In the second type of sorption curve what is probably happening is the saturation of the surface available for water sorption at $\mathrm{RH}$ higher than $75 \%$ and higher $\mathrm{RH}$ produces a smaller increase in the water sorption rate. The first type of sorption curve is associated with trehalose and Hydrovance, while the second sorption behaviour is seen in films plasticized with PEG200 and glycerol at 20\%.

Except for $\mathrm{F}_{\mathrm{CH}}$ at $100 \% \mathrm{RH}$ and $\mathrm{F}_{\mathrm{CT}}$ at $75 \% \mathrm{RH}$, there is no statistical difference between the water amounts in the films composed of chitosan and Carbopol, see Fig. 5(a). It is concluded that the water sorption of the chitosan/Carbopol films is less sensitive to the influence of the additives than chitosan/Noveon films.

$\mathrm{F}_{\mathrm{CH}}$ absorbed an amount of water significantly higher than the respective control while $\mathrm{F}_{\mathrm{CT}}$ had absorbed less water than the control, a characteristic that may in part justify the decrease in the values of EB\% produced by trehalose (Fig. 5(a)) as discussed earlier. The decrease in the water sorption may be explained by the replacement of strongly immobilized water in the polymer chains by trehalose and is in accordance with the low hygroscopic nature of the molecule itself [53]. The exact same behaviour was verified for $\mathrm{F}_{\mathrm{NH}}$ and $\mathrm{F}_{\mathrm{NT}}$, suggesting that Hydrovance has only a significant influence $(P<0.05)$ at very high $\mathrm{RH}$ in the increase of the water content while trehalose induces a decrease of the water content at $75 \%$ RH.

With respect to the influence of $30 \%$ and $40 \%$ glycerol content in the water sorption curves it can be seen in Fig. 5(b) that there is a 

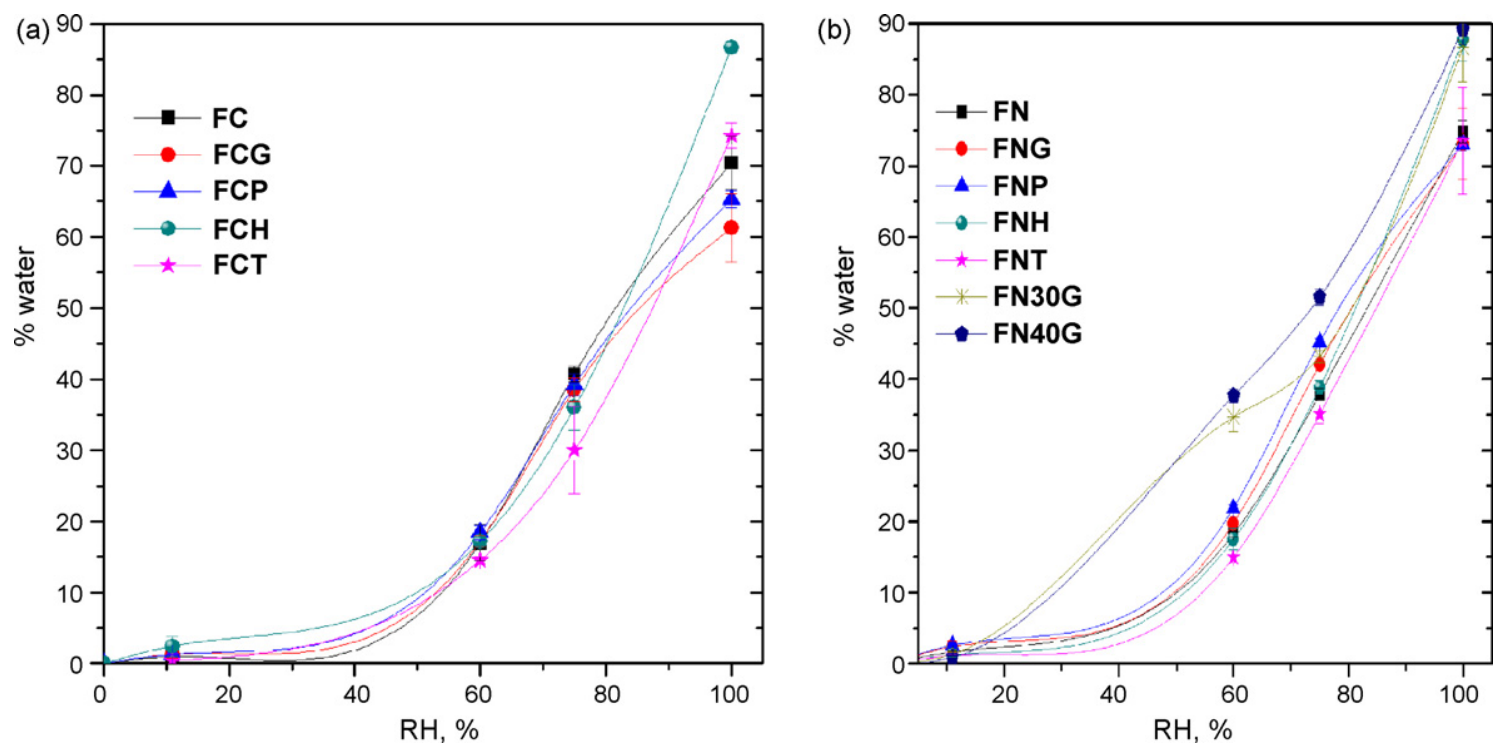

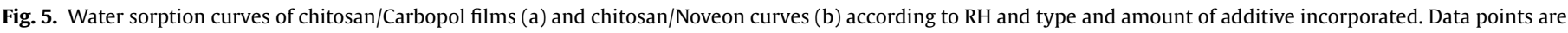
connected by spline lines.

statistically significant difference in the amount of water absorbed in all the range of $\mathrm{RH}(P<0.05)$, although this difference is higher at low RH. Also the shape is not typical but it is important to emphasize that the water content is much less influenced by the RH than in the other films. In fact, the typical "inflexion" point in the sorption curves of other PEC films located at approximately $40-50 \% \mathrm{RH}$, that separates a regime where there is a small uptake of water and a second regime $(>50 \% \mathrm{RH})$ where there is an exponential increase in the water uptake, cannot be observed in the $\mathrm{F}_{\mathrm{N} 30 \mathrm{G}}$ film. This is important in films that are intended to be applied on the skin, because there are no critical $\mathrm{RH}$ values or ranges in which the properties change dramatically.

Higher amounts of plasticizer increase the affinity of films to water, a result that can be attributed to the presence of hydroxyl groups in glycerol that are capable of strongly interact with water [51]. At low water contents glycerol interacts with the polymers via hydrogen bonds and as the amount of water is increased a higher percentage of the hydroxyl groups of glycerol became available for interacting with water [49]. Already at $20 \%$ glycerol $\left(\mathrm{F}_{\mathrm{NG}}\right)$ the films absorbed more water than $\mathrm{F}_{\mathrm{N}}$ between 60 and $75 \% \mathrm{RH}$ and the same behaviour was observed for $\mathrm{F}_{\mathrm{NP}}$.

These results clearly indicate that the water sorption of the chitosan/Carbopol PEC is much less influenced by the incorporation of the additives than the chitosan/Noveon PEC. The incorporation of an amount of glycerol equal or higher than $30 \%$ in the chitosan/Noveon PEC gives rise to films with a water uptake less affected by the RH. This implies that the mechanical properties of the optimized formulation $\left(\mathrm{F}_{\mathrm{Na}}\right)$ will be relatively stable over a wide range of ambient humidity, as is desirable for such a film.

\subsubsection{WVTR}

There is a non-negligible transepidermal water loss (TEWL) of about $5-10 \mathrm{~g} \mathrm{~m}^{-2} \mathrm{~h}^{-1}$ in healthy human skin [54-56] that is necessary to hydrate the outer layers, to maintain its flexibility, for temperature control and to allow enzymatic activity [57]. The application on the skin of any membrane that interferes with the normal TEWL, e.g. water-impermeable membranes, causes profound effects on the skin barrier such as increasing the percutaneous absorption of applied chemicals and the alteration of epidermal lipids, DNA synthesis, surface $\mathrm{pH}$ and bacterial flora
[58-60]. Furthermore, the TEWL itself is a signal to the normalization of the stratum corneum barrier function [61]. For this reason, the investigation of the permeability to moisture (WVTR) of the films to be applied in the skin is of major importance. WVTR also serves to indirectly evaluate the density of PEC and it is simultaneously dependent on the solubility coefficient and diffusion rate of water in the film [49].

WVTR of the films can be found in Table 2. Values range from 13.4 $\left(\mathrm{F}_{\mathrm{CH}}\right)$ to $20.1 \mathrm{~g} \mathrm{~m}^{-2} \mathrm{~h}^{-1}\left(\mathrm{~F}_{\mathrm{N} 30 \mathrm{G}}\right)$ and it should be noticed that all the values measured are higher than the normal TEWL in healthy human skin [54-56]. These values are much higher than the values measured in crosslinked chitosan films that ranged from 0.12 to $0.42 \mathrm{~g} \mathrm{~m}^{-2} \mathrm{~h}^{-1}[62]$.

PEG200 and trehalose do not have a significant influence $(P<0.05)$ in the WVTR of the films and only Hydrovance induces a significant decrease in the WVTR of $\mathrm{F}_{\mathrm{CH}}$ probably due to same reduction of the film porosity since this is not related with a smaller amount of water in the films compared with the unplasticized film as depicted in Fig. 5(a). Interestingly, Hydrovance and glycerol increased the WVTR of chitosan/Noveon films in the following order: $\mathrm{F}_{\mathrm{N}}<\mathrm{F}_{\mathrm{NH}}<\mathrm{F}_{\mathrm{NG}}<\mathrm{F}_{\mathrm{N} 40 \mathrm{G}}<\mathrm{F}_{\mathrm{N} 30 \mathrm{G}}$. This behaviour follows exactly the increase in the $\mathrm{EB} \%$ of the same formulations and may be related with a higher amount of water sorbed in the films with Hydrovance and glycerol, Fig. 5(b). Films with higher water content show increased capacity to water diffusion since they contain more water. Probably an increase in the WVTR values reflects a less compact structure, a higher mobility of the polymer chains and thus an increased flexibility. In earlier studies glycerol also induced an increase in the WVTR of films composed of Ncarboxymethylchitosan and chitosan [63] and potato starch-based films [49].

With respect to the influence of the adhesive layer in the WVTR of the films, it can be seen that this layer reduces the WVTR when compared with the $\mathrm{F}_{\mathrm{N} 30 \mathrm{G}}$, although there is no significant difference between $\mathrm{F}_{\mathrm{Na}}$ and $\mathrm{F}_{\mathrm{N}}$. We can conclude that since the WVTR of the $F_{\mathrm{Na}}$ is $14.2 \mathrm{~g} \mathrm{~m}^{-2} \mathrm{~h}^{-1}$ and higher than the normal TEWL in human skin this film is suitable for application in the skin for a long time without a significant interference in the barrier function of the skin or causing skin sensitization. 


\subsubsection{Bioadhesion}

Skin adhesion is one of the most important functional properties for a skin drug delivery system [29] and should be evaluated in all formulations in development for this purpose. The in vitro conditions do not represent the performance of a film under in vivo conditions due to skin properties, such as moisture and elasticity that are not possible to reproduce in the in vitro test. Most of the in vivo bioadhesive tests are based on subjective observations resorting to scoring systems [29,64]. We use skin in vivo as the substrate for testing adhesive properties and a quantitative evaluation is made by measuring the peak adhesion force and the work of adhesion.

Acrylate polymers are well known skin adhesives [29,30,65]. Our films are composed of chitosan and a PAA but the amount of PAA is only approximately one third of the total polymer weight, a fact that justifies the small values measured for the PAF and WA, see Table 2. The values of PAF in the pure films range from $57.90 \mathrm{mN} / \mathrm{cm}^{2}$ $\left(\mathrm{F}_{\mathrm{NT}}\right)$ to $127.43 \mathrm{mN} / \mathrm{cm}^{2}\left(\mathrm{~F}_{\mathrm{NG}}\right)$ while the values of WA range from $4.94 \times 10^{-5} \mathrm{~mJ} / \mathrm{cm}^{2}\left(\mathrm{~F}_{\mathrm{NT}}\right)$ and $14.30 \times 10^{-5} \mathrm{~mJ} / \mathrm{cm}^{2}\left(\mathrm{~F}_{\mathrm{NG}}\right)$. The plasticizers Hydrovance, PEG200 and 30\% glycerol do not significantly influence $(P>0.005)$ the values of PAF and WA of the films. Trehalose increases the PAF $(P<0.05)$ and the WA of the $F_{C T}$ film, while no difference is observed in the PAF and WA values of $F_{N T}$ when compared with the film in the absence of the additive. Glycerol at $20 \%$ and $40 \%$ induced an increase in the PAF and WA in the films. In a study performed on piroxicam-loaded Eudragit $\mathrm{E}$ films the plasticizer was also able to increase the adhesion strength of the films [46].

The additional layer of the hydrophilic PSA applied to a $F_{N 30 G}$ film produced a dramatic increase in the values of both PAF and WA, $885.45 \mathrm{mN} / \mathrm{cm}^{2}$ and $311.2 \times 10^{-5} \mathrm{~mJ} / \mathrm{cm}^{2}$, respectively. These values represent approximately a 7 -fold and 22 -fold increase, respectively, when compared with the values measured in the film with the best bioadhesive properties $\left(\mathrm{F}_{\mathrm{NG}}\right)$. The adhesion between the PSA and the PEC film is complete. In fact, after the bioadhesion tests no residues of PSA remain on the skin.

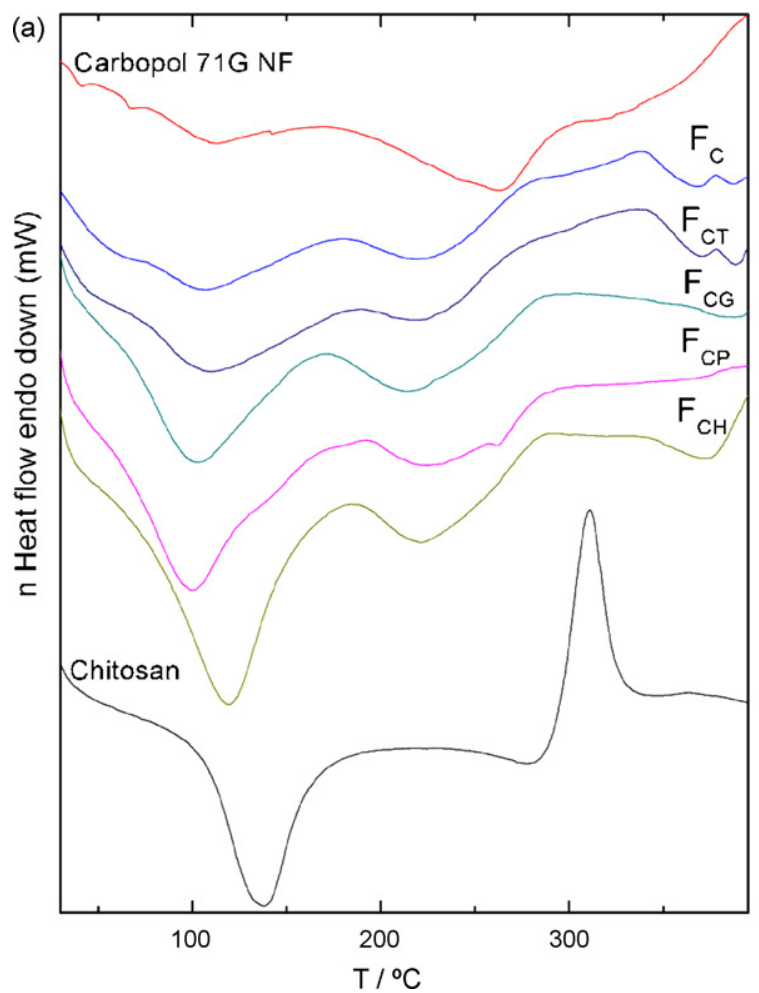

\subsection{Characterization of the polymer-polymer interactions}

DSC and infrared spectroscopy were used for the examination of the interactions between the two oppositely charged polymers in the films.

The DSC thermograms of pure chitosan, Noveon, Carbopol and the films prepared in this study are shown in Fig. 6 while Table 3 presents the endothermic and exothermic peaks detected and the values of enthalpies associated. Pure chitosan exhibits one endothermic peak at $112^{\circ} \mathrm{C}$ associated to the evaporation of absorbed water, a glass transition at $243^{\circ} \mathrm{C}$ and an exothermic peak at about $311^{\circ} \mathrm{C}$ ascribed to the polymer degradation, including saccharide rings dehydration, depolymerization and decomposition of deacetylated and acetylated chitosan units $[48,66]$. These peaks have been reported in several other studies $[26,67]$.

Both forms of PAA exhibit two endothermic peaks with onset temperatures of $\mathrm{ca} .103^{\circ} \mathrm{C}$ and $\sim 243^{\circ} \mathrm{C}$ for Noveon while for Carbopol the onset temperatures are $\sim 80^{\circ} \mathrm{C}$ and $\sim 200^{\circ} \mathrm{C}$, see Table 3 and Fig. 6 . The first endothermic peak has been assigned to the evaporation of water from hydrophilic groups in the polymers and the second one corresponds to a thermal degradation through intramolecular anhydride formation and water elimination [68-71]. After the second endothermic peak, the onset of a broad exothermic peak $\left(\sim 300^{\circ} \mathrm{C}\right)$ is visible in the thermograms, Fig. 6. It is probably related with a second degradation process involving the destruction of carboxylic groups with $\mathrm{CO}_{2}$ elimination and chain scission $[69,70]$.

Several glass transitions $\left(T_{\mathrm{g}}\right)$ were detected in the DSC curves of the two forms of PAA at ca. $41^{\circ} \mathrm{C}$ and $65^{\circ} \mathrm{C}$ for Noveon and ca. $37^{\circ} \mathrm{C}$, $68^{\circ} \mathrm{C}$ and $140^{\circ} \mathrm{C}$ for Carbopol that have been also reported by other authors in the literature [15,68-71]. The $T_{\mathrm{g}}$ detected below $100^{\circ} \mathrm{C}$ are probably related with the presence of residual amounts of solvents used in the polymer synthesis that may act as plasticizers. The glass transition of Carbopol detected at ca. $140{ }^{\circ} \mathrm{C}$ may be explained

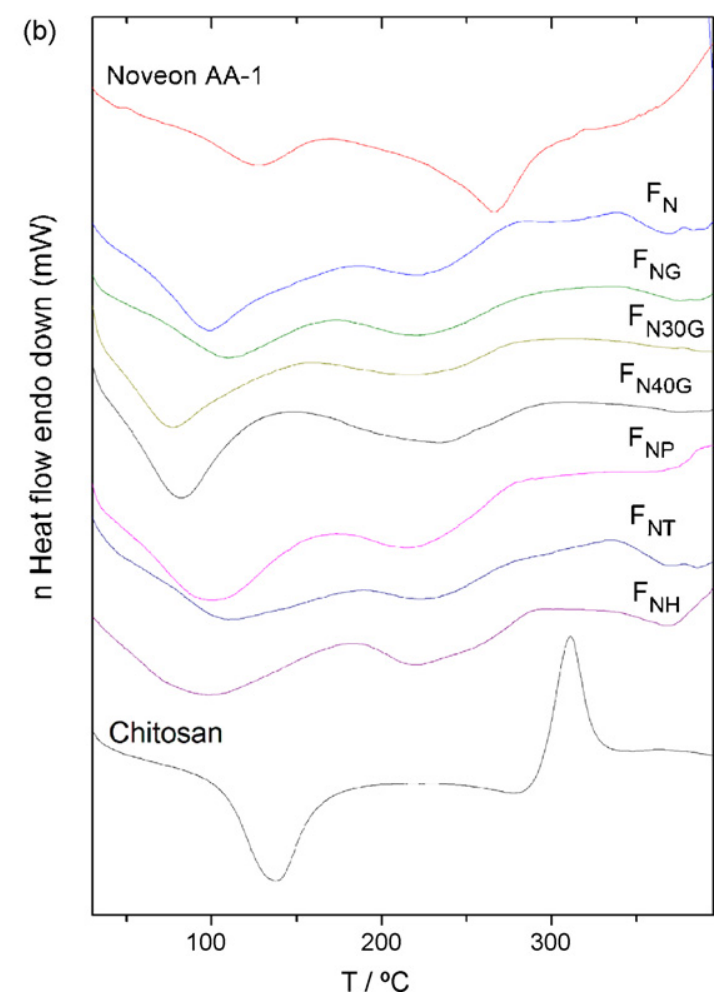

Fig. 6. The DSC thermograms of chitosan, Carbopol, Noveon and PEC films made at the same analytical condition. 
(a)

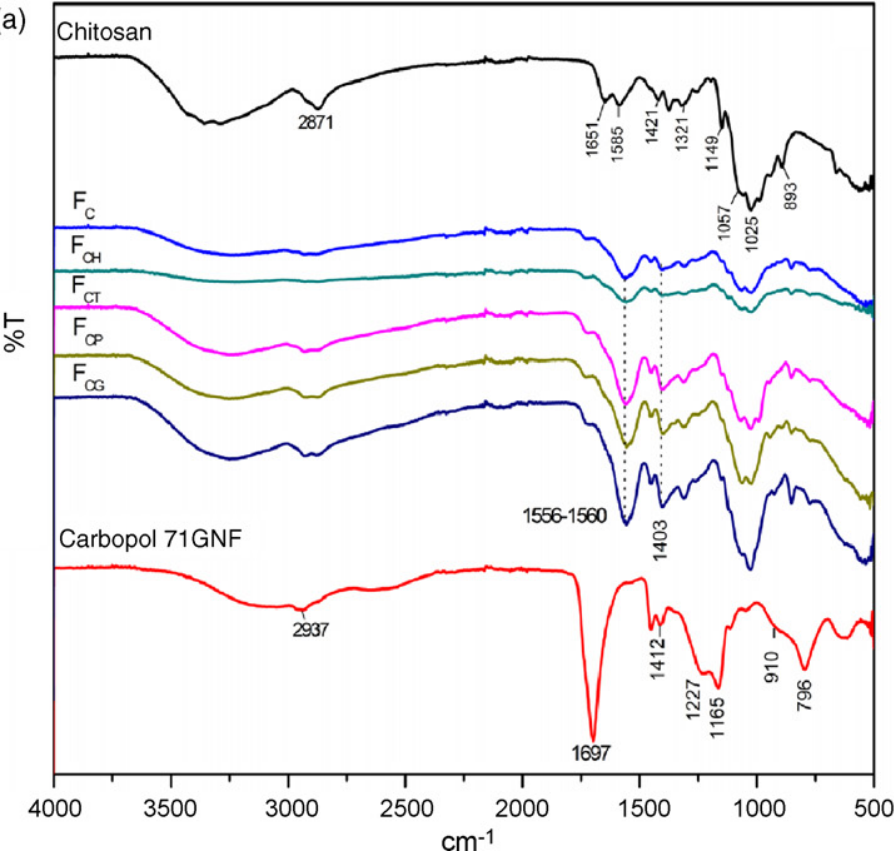

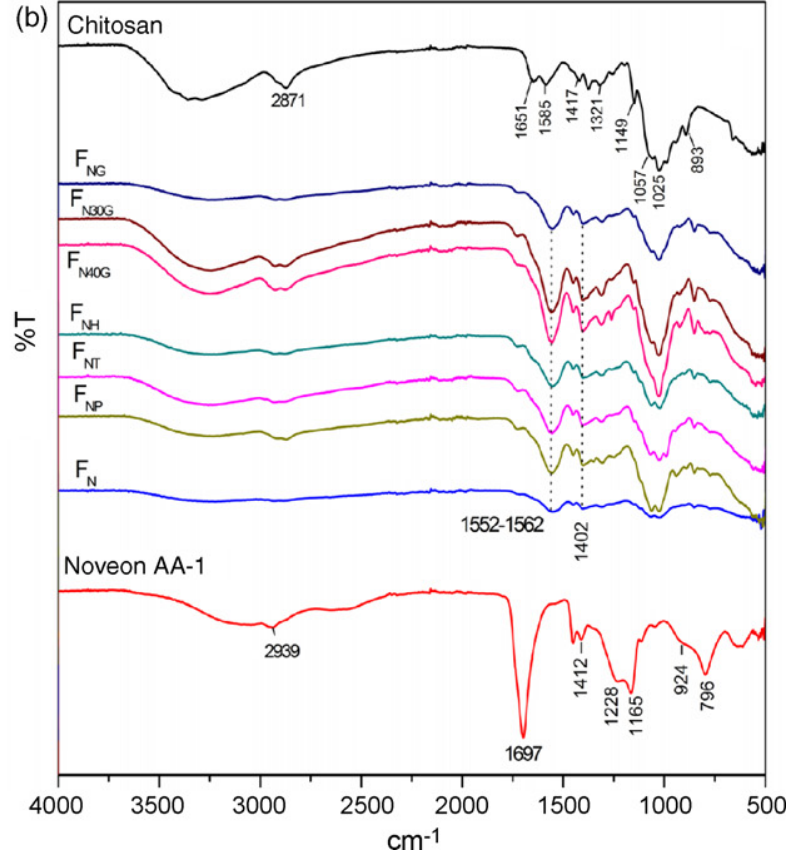

Fig. 7. The FTIR-ATR spectra of chitosan, Carbopol, Noveon and PEC films.

Table 3

Peak temperatures and enthalpy changes detected in the DSC thermograms of the pure polymers and the PEC films

\begin{tabular}{|c|c|c|c|c|}
\hline \multirow[t]{2}{*}{ Sample } & \multicolumn{3}{|c|}{ Temperature $\left({ }^{\circ} \mathrm{C}\right)$} & \multirow[t]{2}{*}{$\Delta H\left(\mathrm{Jg}^{-1}\right)$} \\
\hline & Onset & Peak & Endset & \\
\hline Chitosan & $\begin{array}{r}85.3 \\
291.8\end{array}$ & $\begin{array}{l}112.0 \\
311.0\end{array}$ & $\begin{array}{l}133.9 \\
322.6\end{array}$ & $\begin{array}{r}-180.31 \\
336.32\end{array}$ \\
\hline Noveon AA-1 & $\begin{array}{l}102.6 \\
242.7\end{array}$ & $\begin{array}{l}128.3 \\
265.1\end{array}$ & $\begin{array}{l}153.2 \\
287.3\end{array}$ & $\begin{array}{c}-54.6233 \\
-150.627\end{array}$ \\
\hline Carbopol 71G NF & $\begin{array}{r}79.6 \\
200.0\end{array}$ & $\begin{array}{l}102.3 \\
246.3\end{array}$ & $\begin{array}{l}121.2 \\
280.0\end{array}$ & $\begin{array}{r}-51.10 \\
-239.52\end{array}$ \\
\hline $\mathrm{F}_{\mathrm{N}}$ & $\begin{array}{r}82.1 \\
191.8\end{array}$ & $\begin{array}{r}95.4 \\
221.0\end{array}$ & $\begin{array}{l}122.8 \\
241.3\end{array}$ & $\begin{array}{r}-117.92 \\
-37.99\end{array}$ \\
\hline $\mathrm{F}_{\mathrm{NG}}$ & $\begin{array}{r}78.3 \\
186.1\end{array}$ & $\begin{array}{l}107.6 \\
219.1\end{array}$ & $\begin{array}{l}145.6 \\
248.7\end{array}$ & $\begin{array}{c}-139.567 \\
-62.45\end{array}$ \\
\hline$F_{30 N G}$ & $\begin{array}{r}52.5 \\
181.2\end{array}$ & $\begin{array}{r}76.8 \\
219.2\end{array}$ & $\begin{array}{r}110.1 \\
247.7\end{array}$ & $\begin{array}{l}-273.86 \\
-126.73\end{array}$ \\
\hline $\mathrm{F}_{40 \mathrm{NG}}$ & $\begin{array}{r}62.1 \\
178.8\end{array}$ & $\begin{array}{r}88.7 \\
231.6\end{array}$ & $\begin{array}{r}114.6 \\
278.1\end{array}$ & $\begin{array}{l}-304.17 \\
-182.06\end{array}$ \\
\hline $\mathrm{F}_{\mathrm{NP}}$ & $\begin{array}{r}63.6 \\
191.0\end{array}$ & $\begin{array}{r}99.0 \\
216.8\end{array}$ & $\begin{array}{l}140.1 \\
240.4\end{array}$ & $\begin{array}{r}-211.12 \\
-42.36\end{array}$ \\
\hline $\mathrm{F}_{\mathrm{NH}}$ & $\begin{array}{r}59.4 \\
195.7\end{array}$ & $\begin{array}{r}84.8 \\
218.8\end{array}$ & $\begin{array}{l}134.1 \\
262.6\end{array}$ & $\begin{array}{r}-162.43 \\
-47.37\end{array}$ \\
\hline $\mathrm{F}_{\mathrm{NT}}$ & $\begin{array}{r}77.4 \\
196.7\end{array}$ & $\begin{array}{r}111.1 \\
223.1\end{array}$ & $\begin{array}{l}143.8 \\
252.7\end{array}$ & $\begin{array}{r}-124.42 \\
-36.92\end{array}$ \\
\hline $\mathrm{F}_{\mathrm{C}}$ & $\begin{array}{r}73.5 \\
193.7\end{array}$ & $\begin{array}{l}104.1 \\
219.2\end{array}$ & $\begin{array}{l}154.0 \\
279.7\end{array}$ & $\begin{array}{r}-142.36 \\
-35.78\end{array}$ \\
\hline $\mathrm{F}_{\mathrm{CG}}$ & $\begin{array}{r}75.1 \\
181.2\end{array}$ & $\begin{array}{l}103.8 \\
211.5\end{array}$ & $\begin{array}{r}147.7 \\
252.7\end{array}$ & $\begin{array}{r}-187.62 \\
-53.58\end{array}$ \\
\hline $\mathrm{F}_{\mathrm{CP}}$ & $\begin{array}{r}62.0 \\
201.6\end{array}$ & $\begin{array}{r}92.1 \\
223.7\end{array}$ & $\begin{array}{l}121.1 \\
253.8\end{array}$ & $\begin{array}{r}-309.42 \\
-32.36\end{array}$ \\
\hline $\mathrm{F}_{\mathrm{CH}}$ & $\begin{array}{r}61.2 \\
193.9\end{array}$ & $\begin{array}{r}94.5 \\
219.7\end{array}$ & $\begin{array}{l}148.7 \\
260.5\end{array}$ & $\begin{array}{r}-249.36 \\
-61.37\end{array}$ \\
\hline $\mathrm{F}_{\mathrm{CT}}$ & $\begin{array}{r}81.9 \\
199.3\end{array}$ & $\begin{array}{l}110.4 \\
218.9\end{array}$ & $\begin{array}{l}154.7 \\
237.2\end{array}$ & $\begin{array}{r}-128.4 \\
-19.6\end{array}$ \\
\hline
\end{tabular}

by the disruption of the hydrogen bonds between carboxylic acid groups [15,72].

The PEC films prepared in the present study exhibit two endothermic peaks. The first one is associated with the vapourization of water and the onset temperature is situated between $\sim 53^{\circ} \mathrm{C}\left(\mathrm{F}_{\mathrm{N} 30 \mathrm{G}}\right)$ and $\sim 82{ }^{\circ} \mathrm{C}\left(\mathrm{F}_{\mathrm{N}}\right)$ in the case of chitosan/Noveon films and between $\sim 61{ }^{\circ} \mathrm{C}\left(\mathrm{F}_{\mathrm{CH}}\right)$ and $\sim 82{ }^{\circ} \mathrm{C}\left(\mathrm{F}_{\mathrm{CT}}\right)$ in the chitosan/Carbopol films. The second endothermic peak is probably related with the cleavage of the electrostatic interactions between the oppositely charged polymers, since it is not observed for the pure compounds [67]. The onset temperature of this new transition increases in the following order $\mathrm{F}_{\mathrm{N} 40 \mathrm{G}}<\mathrm{F}_{\mathrm{N} 30 \mathrm{G}}<\mathrm{F}_{\mathrm{NG}}<\mathrm{F}_{\mathrm{NP}} \sim \mathrm{F}_{\mathrm{N}}<\mathrm{F}_{\mathrm{NH}}<\mathrm{F}_{\mathrm{NT}}$ for the chitosan/Noveon films and $\mathrm{F}_{\mathrm{CG}}<\mathrm{F}_{\mathrm{C}} \sim \mathrm{F}_{\mathrm{CH}}<\mathrm{F}_{\mathrm{CT}}<\mathrm{F}_{\mathrm{CP}}$ for chitosan/Carbopol films, Fig. 6 and Table 3. From these results, we can conclude that increasing amounts of glycerol tend to decrease the thermal stability of the polyelectrolyte complexes probably by inserting itself between the polymeric chains. Hydrovance has little influence in the thermal stability of the films and PEG200, in the other hand, does not influence the thermal stability of chitosan/Noveon films, but increases the stability of chitosan/Carbopol polyelectrolyte complexes. Trehalose always increases the thermal stability of the polyelectrolyte complexes as depicted in Fig. 6 and Table 3.

The FTIR-ATR spectra of chitosan, Noveon, Carbopol and the PEC films are shown in Fig. 7. The FTIR-ATR spectrum of chitosan shows a weak band at $2871 \mathrm{~cm}^{-1}$ attributed to the $\mathrm{C}-\mathrm{H}$ stretching and the absorption band due to the carbonyl group stretching of the secondary amide $(\mathrm{C}=\mathrm{O}-\mathrm{NHR})$ appears at $1651 \mathrm{~cm}^{-1}$ indicating that chitosan is not totally deacetylated in accordance with the results obtained in the potentiometric titration $[39,67,73]$. The peaks at 1585,1421 and $1321 \mathrm{~cm}^{-1}$ correspond to the $\mathrm{N}-\mathrm{H}$ bending vibration (amine I band), $\mathrm{N}-\mathrm{H}$ stretching of the amide and ether bonds and the amide III band, respectively [39,67,73]. The peaks at 1149 , 1057,1025 and $893 \mathrm{~cm}^{-1}$ correspond to the bridge oxygen $(\mathrm{C}-\mathrm{O}-\mathrm{C}$ ) stretching bands [73].

The FTIR-ATR spectrum of Noveon in Fig. 7(b) exhibits a broad band at $3100 \mathrm{~cm}^{-1}$, a weak band at $2939 \mathrm{~cm}^{-1}$ and 
a strong band at $1697 \mathrm{~cm}^{-1}$ assigned to the $\mathrm{O}-\mathrm{H}$ stretching (hydrogen-bonded), asymmetric $\mathrm{CH}_{2}$ stretching and $\mathrm{C}=\mathrm{O}$ stretching (hydrogen-bonded), respectively [72-74]. The weak band at $1412 \mathrm{~cm}^{-1}$ is due to the symmetric stretching of carboxylate anion $\left(\mathrm{COO}^{-}\right)$, bands 1228 and $1165 \mathrm{~cm}^{-1}$ are attributed to the $\mathrm{C}-\mathrm{O}$ stretching and, finally, the bands located at 924 and $796 \mathrm{~cm}^{-1}$ are assigned to the $\mathrm{C}-\mathrm{O}-\mathrm{H}$ out-of-plane bending and $\mathrm{CH}_{2}$ twisting, see Fig. 7(b) [15,72-75]. The same bands with minor shifts and the same assignments can be observed in the FTIR-ATR spectrum of Carbopol in Fig. 7(a).

When two immiscible polymers are brought together, it is expected that the resulting infrared spectrum will be the sum of the spectra of the individual compounds because the polymers will have the same environment of the pure state [74]. When the polymers are by contrary miscible, intermolecular interactions may occur and will be reflected in changes on the infrared spectra of the mixture such as wavenumber shifts, band broadening and new absorption bands that are evidence of the polymers miscibility [74]. Furthermore, the films are prepared at $\mathrm{pH} 6.1$ and at this point the degree of ionization of the polymers is approximately $50 \%$, see Fig. 1. For this reason it is expected to find the characteristic absorption bands of the $\mathrm{NH}_{3}{ }^{+}$and $\mathrm{COO}^{-}$groups in the FTIR-ATR spectra of the films.

A new and strong peak located between 1552 and $1562 \mathrm{~cm}^{-1}$ in the chitosan/Noveon films and between 1556 and $1560 \mathrm{~cm}^{-1}$ in the chitosan/Carbopol films can be observed in the FTIR-ATR spectra of each film in Fig. 7. This band can be attributed to the overlapping of the peaks due to the asymmetric COO-stretching vibration of PAA and the $\mathrm{NH}_{3}{ }^{+}$asymmetric bending vibration of chitosan that are reported in the literature to be located between $1550-1610 \mathrm{~cm}^{-1}$ and $1570-1620 \mathrm{~cm}^{-1}$, respectively [73,75,76]. This result clearly indicates the formation of the polyelectrolyte complex between chitosan and the PAA in the absence and in the present of additive contents as high as $40 \%$. Another peak detected in all films at approximately $1402 \mathrm{~cm}^{-1}$ is a further evidence of the interaction because it is attributed to the symmetric $\mathrm{COO}^{-}$stretching vibration $[15,73,74,76]$.

\section{Conclusions}

PEC films with maximized electrostatic interactions were successfully prepared from chitosan and two PAA polymers with different crosslinkers and crosslinking density. The PEC films prepared are thin, with a smooth and uniform surface morphology and a very dense cross-sectional morphology. The formation of the PEC was confirmed by FTIR-ATR and DSC and it is possible to incorporate additives up to $40 \%$ of the dry polymer weight without disturbing the formation of the PEC. Chitosan/Noveon films are shown to be more flexible and more permeable to water than the correspondent chitosan/Carbopol films. PEG200 and trehalose decreased the flexibility of the films and glycerol was provided the best film properties, optimizing flexibility, resistance and WVTR at the 30\% level. The PSA significantly improved bioadhesion without a significant effect upon the resistance and flexibility of the films.

The optimized film $\left(\mathrm{F}_{\mathrm{Na}}\right)$ has shown very good flexibility, resistance and bioadhesion which make it a very promising film for application in the skin. Also the WVTR measured is higher than the normal TEWL so this film can be applied on skin without the risk of a significant interference in the barrier function or causing sensitization due to occlusion.

The development of this film will be continued with the incorporation of different drugs and by the determination of the drug release profiles and drug permeation through the skin in order to evaluate the feasibility of using these films as versatile skin delivery systems.

\section{Acknowledgements}

CLS acknowledges Fundação para a Ciência e Tecnologia for a PhD grant, ref. SFRH/BD/14213/2003. The authors wish to thank Lubrizol Advance Materials Inc. who kindly provided the Noveon AA- ${ }^{\circledR}$, Carbopol $71 \mathrm{G}$ and National Starch \& Chemical Company for Hydrovance.

\section{References}

[1] M. Brown, G. Martin, S. Jones, F. Akomeah, Dermal and transdermal drug delivery systems: current and future prospects, Drug Deliv. 13 (2006) 175.

[2] N.A. Peppas, P. Bures, W. Leobandung, H. Ichikawa, Hydrogels in pharmaceutical formulations, Eur. J. Pharm. Biopharm. 50 (2000) 27.

[3] J. Berger, M. Reist, J.M. Mayer, O. Felt, R. Gurny, Structure and interactions in chitosan hydrogels formed by complexation or aggregation for biomedical applications, Eur. J. Pharm. Biopharm. 57 (2004) 35.

[4] J. Berger, M. Reist, J.M. Mayer, O. Felt, N.A. Peppas, R. Gurny, Structure and interactions in covalently and ionically crosslinked chitosan hydrogels for biomedical applications, Eur. J. Pharm. Biopharm. 57 (2004) 19.

[5] J.W. Lee, S.Y. Kim, S.S. Kim, Y.M. Lee, K.H. Lee, S.J. Kim, Synthesis and characteristics of interpenetrating polymer network hydrogel composed of chitosan and poly(acrylic acid), J. Appl. Polym. Sci. 73 (1999) 113.

[6] A. Denuziere, D. Ferrier, O. Damour, A. Domard, Chitosan-chondroitin sulfate and chitosan-hyaluronate polyelectrolyte complexes: biological properties, Biomaterials 19 (1998) 1275.

[7] E. Khor, L.Y. Lim, Implantable applications of chitin and chitosan, Biomaterials 24 (2003) 2339

[8] S. Rossi, G. Sandri, F. Ferrari, M.C. Bonferoni, C. Caramella, Buccal delivery of acyclovir from films based on chitosan and polyacrylic acid, Pharm. Dev. Technol. 8 (2003) 199.

[9] P. Torre, Y. Enobakhare, G. Torrado, S. Torrado, Release of amoxicillin from polyionic complexes of chitosan and poly(acrylic acid). Study of polymer/polymer and polymer/drug interactions within the network structure, Biomaterials 24 (2003) 1499.

[10] T. Cerchiara, B. Luppi, F. Bigucci, I. Orienti, V. Zecchi, Physically cross-linked chitosan hydrogels as topical vehicles for hydrophilic drugs, J. Pharm. Pharmacol. 54 (2002) 1453.

[11] N.L. Yusof, A. Wee, L.Y. Lim, E. Khor, Flexible chitin films as potential wound dressing materials: wound model studies, J. Biomed. Mater. Res. 66A (2003) 224.

[12] A.K. Azad, N. Sermsintham, S. Chandrkrachang, W.F. Stevens, Chitosan membrane as a wound-healing dressing: characterization and clinical application, J Biomed. Mater. Res. Part B: Appl. Biomater. 69B (2004) 216.

[13] J. Nunthanid, S. Puttipipatkhachorn, K. Yamamoto, G.E. Peck, Physical properties and molecular behavior of chitosan films, Drug Dev. Ind. Pharm. 27 (2001) 143.

[14] P.M. Torre, S. Torrado, S. Torrado, Interpolymer complexes of poly(acrylic acid) and chitosan: influence of the ionic hydrogel-forming medium, Biomaterials 24 (2003) 1459.

[15] A. Gómez-Carracedo, C. Alvarez-Lorenzo, J.L. Gómez-Amoza, A. Concheiro, Glass transitions and viscoelastic properties of carbopol and noveon compacts, Int. J. Pharm. 274 (2004) 233.

[16] X.Z. Shu, K.J. Zhu, W. Song, Novel pH-sensitive citrate cross-linked chitosan film for drug controlled release, Int. J. Pharm. 212 (2001) 19.

[17] K. Kofuji, T. Ito, Y. Murata, S. Kawashima, Effect of chondroitin sulfate on the biodegradation and drug release of chitosan gel beads in subcutaneous air pouches of mice, Biol. Pharm. Bull. 25 (2002) 268

[18] O. Munjeri, J.H. Collett, J.T. Fell, Hydrogel beads based on amidated pectins for colon-specific drug delivery: the role of chitosan in modifying drug release, J. Control. Release 46 (1997) 273.

[19] W. Chen, L. Wang, J. Chen, S. Fan, Characterization of polyelectrolyte complexes between chondroitin sulfate and chitosan in the solid state, J. Biomed. Mater. Res. 75A (2005) 128.

[20] J.-S. Ahn, H.-K. Choi, M.-K. Chun, J.-M. Ryu, J.-H.Jung, Y.-U. Kim, C.-S. Cho, Release of triamcinolone acetonide from mucoadhesive polymer composed of chitosan and poly(acrylic acid) in vitro, Biomaterials 23 (2002) 1411.

[21] H. Lin, S. Yu, C. Kuo, H. Kao, Y. Lo, Y. Lin, Pilocarpine-loaded chitosan-PAA nanosuspension for ophthalmic delivery, J. Biomater. Sci. Polym. Ed. 18 (2007) 205.

[22] A.J. Thote, J.T. Chappell, R. Kumar, R.B. Gupta, Reduction in the initial-burst release by surface crosslinking of PLGA microparticles containing hydrophilic or hydrophobic drugs, Drug Dev. Ind. Pharm. 31 (2005) 43.

[23] X. Huang, C.S. Brazel, On the importance and mechanisms of burst release in matrix-controlled drug delivery systems, J. Control. Release 73 (2001) 121

[24] P.M.d.l. Torre, G. Torrado, S. Torrado, Poly(acrylic acid) chitosan interpolymer complexes for stomach controlled antibiotic delivery, J. Biomed. Mater. Res. Part B: Appl. Biomater. 72B (2005) 191. 
[25] I.S. Arvanitoyannis, A. Nakayama, S. Aiba, Chitosan and gelatin based edible films: state diagrams, mechanical and permeation properties, Carbohydr. Polym. 37 (1998) 371.

[26] N.E. Suyatma, L. Tighzert, A. Copinet, Effects of hydrophilic plasticizers on mechanical, thermal, and surface properties of chitosan films, J. Agric. Food Chem. 53 (2005) 3950.

[27] R. Rowe, P. Sheskey, S. Owen, Handbook of Pharmaceutical Excipients, Pharmaceutical Press, 2005.

[28] N.S.C. Company, Hydrovance ${ }^{\mathrm{TM}}$ Moisturizing Agent (28-041A) (2005) 1.

[29] A.M. Wokovich, S. Prodduturi, W.H. Doub, A.S. Hussain, L.F. Buhse, Transdermal drug delivery (TDDS) adhesion as a critical safety, efficacy and quality attribute, Eur. J. Pharm. Biopharm. 64 (2006) 1.

[30] S. Venkatraman, R. Gale, Skin adhesives and skin adhesion. 1. Transdermal drug delivery systems, Biomaterials 19 (1998) 1119.

[31] M.M. Feldstein, I.M. Raigorodskii, A.L. Iordanskii, J. Hadgraft, Modeling of percutaneous drug transport in vitro using skin-imitating Carbosil membrane, J. Control. Release 52 (1998) 25.

[32] A.L. Iordanskii, M.M. Feldstein, V.S. Markin, J. Hadgraft, N.A. Plate, Modeling of the drug delivery from a hydrophilic transdermal therapeutic system across polymer membrane, Eur. J. Pharm. Biopharm. 49 (2000) 287.

[33] M.M. Feldstein, V.N. Tohmakhch, L.B. Malkhazov, A.E. Vasiliev, N.A. Plate, Hydrophilic polymeric matrices for enhanced transdermal drug delivery, Int. J. Pharm. 131 (1996) 229.

[34] A.A. Chalykh, A.E. Chalykh, M.B. Novikov, M.M. Feldstein, Pressure-sensitive adhesion in the blends of poly(N-vinyl pyrrolidone) and polyethylene glycol of disparate chain lengths, J. Adhes. 78 (2002) 667.

[35] J.L.G.C. Pereira, A.A.C.C. Pais, J.S. Redinha, Maximum likelihood estimation with nonlinear regression in polarographic and potentiometric studies, Anal. Chim. Acta 433 (2001) 135

[36] R.P. Buck, S. Rondinini, A.K. Covington, F.G.K. Baucke, C.M.A. Brett, M.F. Camões, M.J.T. Milton, T. Mussini, R. Naumann, K.W. Pratt, P. Spitzer, G.S. Wilson, Measurement of $\mathrm{pH}$. Definition, standards, and procedures. (IUPAC Recommendations 2002), Pure Appl. Chem. 74 (2002) 2169-2200.

[37] E. Seyrek, P.L. Dubin, C. Tribet, E.A. Gamble, Ionic strength dependence of protein-polyelectrolyte interactions, Biomacromolecules 4 (2003) 273.

[38] T.A. Khan, K.K. Peh, H.S. Ch'ng, Mechanical, bioadhesive strength and biologica evaluations of chitosan films for wound dressing, J. Pharm. Pharmaceut. Sci. 3 (2000) 303.

[39] K.M. Kim, C.L. Weller, M.A. Hanna, Properties of chitosan films according to $\mathrm{pH}$ and types of solvents, J. Food Sci. 71 (2006) E119.

[40] X. Yan, E. Khor, L. Lim, Chitosan-alginate films prepared with chitosans of different molecular weights, J. Biomed. Mater. Res. (Appl. Biomater.) 58 (2001 358

[41] L.B. Rockland, Saturated salt solutions for static control of relative humidity between $5^{\circ} \mathrm{C}$ and $40^{\circ} \mathrm{C}$, Anal. Chem. 32 (1960) 1375.

[42] A. Roos, C. Creton, M.B. Novikov, M.M.B. Feldstein, Viscoelasticity and tack of poly(vinyl pyrrolidone)-poly(ethylene glycol) blends, J. Polym. Sci. Part B: Polym. Phys. 40 (2002) 2395.

[43] K. Paepe, E. Houben, R. Adam, F. Wiesemann, V. Rogiers, Validation of the VapoMeter, a closed unventilated chamber system to assess transepidermal water loss vs. the open chamber Tewameter ${ }^{\circledR}$, Skin Res. Technol. 11 (2005) 61-69.

[44] S. Ikeda, H. Kumagai, T. Sakiyama, C. Chu, K. Nakamura, Method for analyzing $\mathrm{pH}$-sensitive swelling of amphoteric hydrogels-application to a polyelectrolyte complex gel prepared from xanthan and chitosan, Biosci. Biotech. Biochem. 59 (1995) 1422.

[45] S. Mao, U. Bakowsky, A. Jintapattanakit, T. Kissel, Self-assembled polyelectrolyte nanocomplexes between chitosan derivatives and insulin, J. Pharm. Sci. 95 (2006) 1035

[46] S.Y. Lin, C.J. Lee, Y.Y. Lin, Drug-polymer interaction affecting the mechanical properties, adhesion strength and release kinetics of piroxicam-loaded Eudragit E films plasticized with different plasticizers, J. Control. Release 33 (1995) 375

[47] M.F. Cervera, J. Heinämäki, K. Krogars, A.C. Jörgensen, M. Karjalainen, A. Colarte, J. Yliruusi, Solid-state and mechanical properties of aqueous chitosan-amylose starch films plasticized with polyols, AAPS PharmSciTech 5 (2004) article 15.

[48] S. Mathew, M. Brahmakumar, T.E. Abraham, Microstructural imaging and characterization of the mechanical, chemical, thermal, and swelling properties of starch-chitosan blend films, Biopolymers 82 (2006) 176.

[49] R.A. Talja, H. Helén, Y.H. Roos, K. Jouppila, Effect of various polyols and polyol contents on physical and mechanical properties of potato starch-based films, Carbohydr. Polym. 67 (2007) 288.

[50] M.F. Cervera, M. Karjalainen, S. Airaksinen, J. Rantanen, K. Krogars, J. Heinamaki, A.I. Colarte, J. Yliruusi, Physical stability and moisture sorption of aqueous chitosan-amylose starch films plasticized with polyols, Eur. J. Pharm. Biopharm. 58 (2004) 69.

[51] S. Mali, L.S. Sakanaka, F. Yamashita, M.V.E. Grossmann, Water sorption and mechanical properties of cassava starch films and their relation to plasticizing effect, Carbohydr. Polym. 60 (2005) 283.

[52] S. Despond, E. Espuche, A. Domard, Water sorption and permeation in chitosan films: relation between gas permeability and relative humidity, J. Polym. Sci. Part B: Polym. Phys. 39 (2001) 3114

[53] A.B. Richards, S. Krakowka, L.B. Dexter, H. Schmid, A.P.M. Wolterbeek, D.H. Waalkens-Berendsen, A. Shigoyuki, M. Kurimoto, Trehalose: a review of properties, history of use and human tolerance, and results of multiple safety studies, Food Chem. Toxicol. 40 (2002) 871.

[54] R. Marks, The stratum corneum barrier: the final frontier, J. Nutr. 134 (2004) 2017S.

[55] Y. Kalia, F. Pirot, R. Guy, Homogeneous transport in a heterogeneous membrane: water diffusion across human stratum corneum in vivo, Biophys. J. 71 (1996) 2692-2700.

[56] Y.N. Kalia, I. Alberti, N. Sekkat, C. Curdy, A. Naik, R.H. Guy, Normalization of stratum corneum barrier function and transepidermal water loss in vivo, Pharm. Res. 17 (2000) 1148.

[57] A.V. Rawlings, C.R. Harding, Moisturization and skin barrier function, Dermatol. Ther. 17 (2004) 43.

[58] H. Zhai, H.I. Maibach, Effects of skin occlusion on percutaneous absorption: an overview, Skin Pharmacol. Appl. Skin Physiol. 14 (2001) 1.

[59] R. Aly, C. Shirley, B. Cunico, H.I. Maibach, Effect of prolonged occlusion on the microbial flora, $\mathrm{pH}$, carbon dioxide and transepidermal water loss on Human skin, J. Invest. Dermatol. 71 (1978) 378.

[60] H. Zhai, H.I. Maibach, Occlusion vs. skin barrier functions, Skin Res. Technol. 8 (2002) 1.

[61] G. Grubauer, P.M. Elias, K.R. Feingold, Transepidermal water loss: the signal for recovery of barrier structure and function, J. Lipid Res. 30 (1989) 323.

[62] C. Remunan-Lopez, R. Bodmeier, Mechanical, water uptake and permeability properties of crosslinked chitosan glutamate and alginate films, J. Control. Release 44 (1997) 215.

[63] R. Lamim, R.A. Freitas, E.I. Rudek, H.M. Wilhelm, O.A. Cavalcanti, T.M.B. Bresolin, Films of chitosan and N-carboxymethylchitosan. Part II: effect of plasticizers on their physiochemical properties, Polym. Int. 55 (2006) 970.

[64] J. Viyoch, T. Sudedmark, W. Srema, W. Suwongkrua, Development of hydrogel patch for controlled release of alpha-hydroxy acid contained in tamarind fruit pulp extract, Int. J. Cosm. Sci. 27 (2005) 89.

[65] D.A. Hollingsbee, P. Timmins, Topical Adhesive Systems, Wissenschaftliche Verlagsgesellschaft, Stuttgart, 1990.

[66] B. Sarmento, A. Ribeiro, F. Veiga, D. Ferreira, Development and characterization of new insulin containing polysaccharide nanoparticles, Colloids Surf. B: Biointerfaces 53 (2006) 193.

[67] M.G. Sankalia, R.C. Mashru, J.M. Sankalia, V.B. Sutariya, Reversed chitosan-alginate polyelectrolyte complex for stability improvement of alpha-amylase: optimization and physicochemical characterization, Eur. J. Pharm. Biopharm. 65 (2007) 215.

[68] X.-D. Fan, Y.-L. Hsieh, J.M. Krochta, M.J. Kurth, Study on molecular interaction behavior, and thermal and mechanical properties of polyacrylic acid and lactose blends, J. Appl. Polym. Sci. 82 (2001) 1921.

[69] Y. Huang, J. Lu, C. Xiao, Thermal and mechanical properties of cationic guar gum/poly(acrylic acid) hydrogel membranes, Polym. Deg. Stab. 92 (2007) 1072.

[70] J.J. Maurer, D.J. Eustace, C.T. Ratcliffe, Thermal characterization of poly(acrylic acid), Macromolecules 20 (1987) 196.

[71] C. Rodríguez-Tenreiro, C. Alvarez-Lorenzo, A. Concheiro, J.J. Torres-Labandeira, Characterization of cyclodextrin-carbopol interactions by DSC and FTIR, J. Therm. Anal. Cal. 77 (2004) 403.

[72] J. Dong, Y. Ozaki, K. Nakashima, Infrared, Raman, and near-infrared spectroscopic evidence for the coexistence of various hydrogen-bond forms in poly(acrylic acid), Macromolecules 30 (1997) 1111

[73] K. Brandenburg, U. Seydel, Fourier Transform Infrared Spectroscopy of Cell Surface Polysacharides, Wiley-Liss, New York, 1996.

[74] B. Stuart, Infrared Spectroscopy: Fundamentals and Applications, John Wiley \& Sons Ltd., West Sussex, England, 2004.

[75] J. Coates, Interpretation of Infrared Spectra, A Practical Approach, John Wiley \& Sons Ltd., Chichester, 2000.

[76] C.D. Brown, L. Kreilgaard, M. Nakakura, N. Caram-Lelham, D.K. Pettit, W.R. Gombotz, A.S. Hoffman, Release of PEGylated granulocyte-macrophage colonystimulating factor from chitosan/glycerol films, J. Control. Release 72 (2001) 35 . 